\title{
Semiconductor II-VI Quantum Dots with Interface States and Their Biomedical Applications
}

\author{
Tetyana Torchynska ${ }^{1}$ and Yuri Vorobiev ${ }^{2}$ \\ ${ }^{1}$ ESFM - National Polytechnic Institute, México D. F. \\ ${ }^{2}$ CINVESTAV-IPN, Unidad Querétaro, Querétaro, QRO., \\ México
}

\section{Introduction}

Nanocrystals of group II-VI semiconductors, known as quantum dots (QDs), in which electrons and holes are three dimensionally confined within the exciton Bohr radius of the material, are characterized by the exceptional optical properties, such as broad absorption and sharp emission bands as well as size-tunable photoluminescence in the visible spectral range.

The most popular are CdSe/ZnS QDs due to their bright and unique emission with the wide excitation spectra and narrow emission bandwidths (Bailey et al., 2004; Dybiec et al., 2007; Jamieson et al., 2007; Kune et al., 2001; Norris et al., 1996; Tessler et al., 2002). The II-VI QDs have been investigated in versatile photonic applications including solar cells (Choi et al., 2006; Kongkanand et al., 2008; Lopez-Luke et al., 2008), optical fibre amplifiers (Liu et al., 2007), color displays using light-emitting diode arrays (Huang et al., 2008: Klude et al., 2002; Zhao et al., 2006), optical temperature probes (Liang et al., 2006; Walker et al., 2003), as well as in biology and medicine (Alivisatos et al., 2005; Grodzinski et al., 2006; Hoshino et al., 2007; Murcia et al., 2008; Portney \& Ozkan, 2006; Wang et al., 2007).

Note that metal, semiconductor, polymer and ceramic nanoparticles in general have gained essential interest for biological and medical applications (Brigger, et al., 2002). Polymer and ceramic nanoparticles have been widely used as drug carriers, whereas metal nanoclusters and semiconductor QDs have been applied mainly for imaging and therapy. Among various nanoparticles, semiconductor QDs attracted much attention due their exceptional optical properties. In comparison with organic dyes and fluorescent proteins, the semiconductor quantum-confined core/shell nanostructures, such as CdSe/ZnS QDs, are brighter, more stable against photo bleaching, have multicolor emission in dependence on core sizes and can be excited for this emission with a single light source. The size-tunable properties allow one to choose an emission wavelength that is well suited to experimental conditions and to synthesize the QD-based probe by using an appropriate semiconductor materials and nanocrystal sizes.

In biology and medicine the semiconductor QDs have been used: for the fluorescence resonance energy transfer (FRET) analysis (Bailey et al., 2004; Jamieson et al., 2007; Zhang et al., 2005), in gene technology (Gerion et al., 2002; Han et al., 2001; Pathak et al., 2001), fluorescent labeling of cellular proteins (Dubertret et al., 2002; Dubertret et al., 2003; Hanaki 
et al., 2003), cell tracking (Bailey et al., 2004; Jamieson et al., 2007), pathogen and toxin detections (Lee et al., 1994; Yang et al., 2006), the bioconjugation to different antibodies and the targeted imaging and the delivery of anticancer drugs (Ebenstein et al., 2004; Ferrari et al., 2005; Torchynska 2009a; Torchynska et al., 2009b; Torchynska et al., 2010; Vega Macotela et al., 2010), the tissue, arterial and venous imaging (Larson et al., 2003; Wu et al., 2002), as well as in vivo animal imaging (Gao et al., 2004; Parungo et al., 2005).

The capping by wide band gap semiconductor $(\mathrm{ZnS})$ of CdSe alone is not sufficient to stabilize the core, particularly in biological solutions, but the additional covering of $\mathrm{ZnS}$ shell with polymers or ZnS shell silanization provide increasing in QD stability and a reduction in non-specific adsorption. As a result the core/shell CdSe/ZnS QDs covered with polymers or silanized have improved essentially the efficiency of using of fluorescent markers in biological applications (Ebenstein et al., 2004; Larson et al., 2003; Torchynska, 2009a; Torchynska et al.,, 2010).

The conjugation of biomolecules with QDs has been achieved, as a rule, through covalent bonds using functional groups (linkers) on the QD surface (Gerion et al., 2001; Parak et al., 2002; Wolcott et al., 2006) or with the help of electrostatic interaction between QDs and biomolecules in self-essembled cases (Clapp et al., 2004; Ji et al., 2005; Torchynska 2009a). The essential set of publications related to the study of QD bioconjugation using PL spectroscopy revealed that the PL intensity of QDs decreased (Guo et al., 2003; Ji et al., 2005; Torchynska et al., 2009a; Vega Macotela et al., 2010) or increased (Torchynska et al., 2009a; Torchynska et al., 2009b) owing, as supposed, to the energy exchange between QDs and biomolecules. The shape of PL spectra of these bioconjugated QDs was not changed (Guo et al., 2003; Ji et al., 2005; Torchynska et al., 2009a; Torchynska et al., 2010). However up to now the full impact of bioconjugation processes on optical properties of CdSe/ZnS QDs is not understood completely.

The chapter presents the results of theoretical and experimental investigations of the authors related to the effect of QD dimensions and structure upon their photoluminescence spectra, as well as the influence of bioconjugation on QD emission and Raman scattering spectra, with an emphasis on the role of interface states in recombination processes in QDs. Besides, it contains a brief review of the data published by QDs inventors, producers and investigators necessary for the presentation and discussion of original results.

\section{Synthesis of II-VI semiconductor core/shell QDs and encapsulation}

A set of methods of growing CdSe, CdTe.... QDs have been reported (Crouch et al., 2003; Heine et al., 1998; Lou et al., 2004; Murray et al., 1993; Murray et al., 2000; Murray et al., 2001; Nordell et al., 2005; Park et al., 2004; Rosenthal et al., 2007; Yoon et al., 2005; Yu et al., 2005). The essential elements of these methods involve appropriate metallic or organometallic precursors (zinc, cadmium or mercury) with corresponding chalcogen precursors (sulfur, selenium or tellurium) in a coordinating solvent at high temperatures (Danek et al., 1994; Heine et al., 1998; Lou et al., 2004; Malik et al., 2005; Murray et al., 1993; Murray et al., 2000; Murray et al., 2001; Nann et al., 2002; Peng et al., 2001). The pyrolysis of organometallic precursors of cadmium and Se (or Te) introduced in (Murray et al., 1993; Murray et al., 2000) continues to be a wide used method for synthesizing CdSe or CdTe QDs. Typically CdSe (or CdTe) QDs were synthesized at $230-300^{\circ} \mathrm{C}$ by the reaction between dimethyl cadmium (CdMe2) dissolved in trioctylphosphine (TOP) and TOPSe (or TOPTe) dissolved in TOP or in trioctylphosphine oxide (TOPO). The nucleation process is realized 
after the thermal decomposition of precursor reagents and the supersaturation of formed "monomers" that is relieved by nuclei generation. Monomer concentrations then are below the critical value for the nucleation, as result, the existing particles only grow without the formation of new nucleus (Murray et al., 2001). Time is a key parameter: longer reaction times result to a larger average particle size. Finally the formation of QDs takes place in these reactions, from which individual sizes of QDs were isolated by size-selective precipitation. The most successful system for the preparation of QDs with the high emission efficiency and mono dispersed particles includes a complex mixture of surfactants: stearic acid, TOPO, hexadecylamine, tributylphosphine (TBP), and dioctylamine (Qu \& Peng, 2002). CdSe QDs having relatively small size $(2-5 \mathrm{~nm})$ absorb and emit light in the visible region (Fig.1), as well as CdSe QDs having a core-diameter $5-8 \mathrm{~nm}$ and CdTe QDs absorb and emit light in the deep-red to IR regions, making them potential candidates for in vivo imaging and photodynamic therapy of cancer.
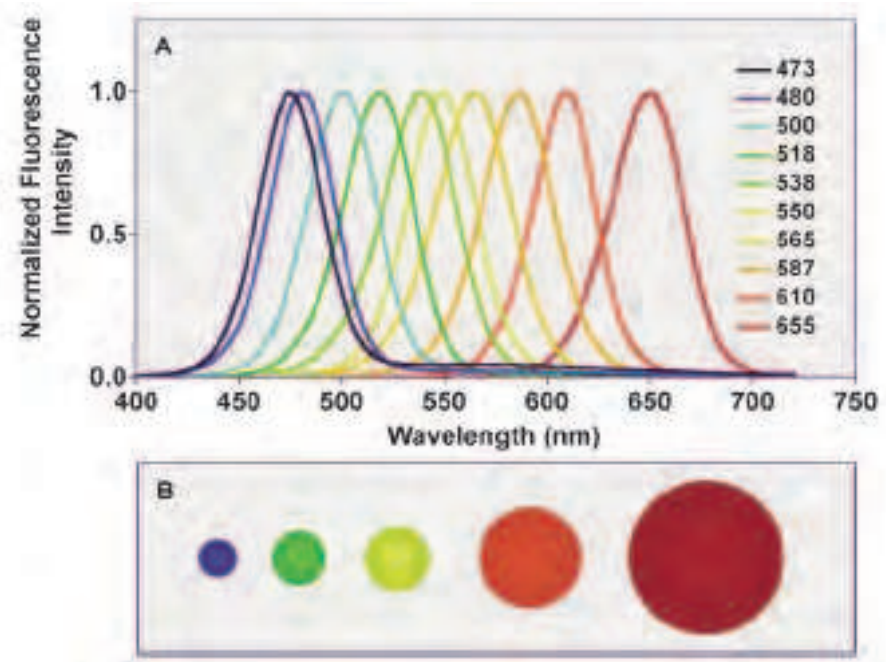

Fig. 1. Size-tunable fluorescence spectra of CdSe quantum dots (A), and illustration of the relative particle sizes (B). From left to right, the particle diameters are $2.1 \mathrm{~nm}, 2.5 \mathrm{~nm}, 2.9$ $\mathrm{nm}, 4.7 \mathrm{~nm}$, and $7.5 \mathrm{~nm}$. (Smith \& Nie, 2004)

Dimethyl cadmium is extremely toxic, expensive, unstable, explosive and pyrophoric, making the mentioned reactions difficult to control. Alternative cadmium precursors such as cadmium oxide, cadmium acetate, have been proposed as safer and greener cadmium precursors (Bilu et al., 2005a; Bilu et al., 2005b; Hai et al., 2009; Park et al., 2008; Peng et al., 2001; Qu et al., 2001). Recently (Peng et al., 2001) the synthesis of CdSe nanocrystals from $\mathrm{CdO}$ and elemental Se was realized, as an example of green chemistry with relatively safe materials, but the hazards associated with the $\mathrm{CdO}$ and Se have not been avoided.

The state of the surface impacts very strongly on optical and electrical properties of semiconductors that require embedding semiconductor clusters in a passivating medium (Alivisatos et al., 1996).

It is well known that the emission intensity of CdSe QDs increases essentially when the CdSe (or CdTe) cores are capped inside a shell of high bandgap material, such as ZnS, to 
form a CdSe/ZnS core-shell QDs. There are some more advantages for core/shell QDs in comparison with core-only QDs. The chemical and physical stabilities of core QDs increase when conjugated or shelled by higher band-gap semiconductors and polymers (Dabbousi et al., 1997; Kim et al., 2003; Peng et al., 1997).

Many types of core/shell QDs were developed such as CdSe/ZnS, CdSe $/ \mathrm{Zn}_{0.2} \mathrm{Cd}_{0.8} \mathrm{~S}$, $\mathrm{CdSe} / \mathrm{CdS}$ and $\mathrm{CdTe} / \mathrm{CdSe}$ etc. Let us discuss the preparation of $\mathrm{ZnS}$ shells on CdSe cores as the best example presented in (Dabbousi et al., 1997). A solvent mixture (10:1) composed of TOPO and TOP was prepared by heating TOPO at $190{ }^{\circ} \mathrm{C}$ under vacuum, cooling to $60^{\circ} \mathrm{C}$ and adding TOP. The CdSe QD suspension was prepared in hexane, transferred into the solvent mixture, and hexane was distilled out. A solution of diethyl zinc and hexamethyldisilathiane in TOP were added into the CdSe QD suspension kept at $140-220^{\circ} \mathrm{C}$, and ZnS shells were grown at this temperature. When required thickness of $\mathrm{ZnS}$ shells was obtained, controlled by absorption spectrum, the reaction was stopped by adding 1-butanol. The reaction mixture was cooled to room temperature, and the core/shell CdSe/ZnS QDs were separated by precipitation from a mixture of 1-butanol and methanol (Dabbousi et al., 1997). Shelling CdSe QDs with CdS resulted in considerable red-shifts in the absorption and photoluminescence bands of CdSe/CdS QDs in comparison with CdSe/ZnS QDs (Kim et al., 2003; Peng et al., 1997). Due to hydrophobic capping of QDs prepared by the methods mentioned above, further surface modification was necessary for biocompatibility.

Encapsulation has typically included incorporating core/shell QDs into organic polymers (Chin 2004; Fogg et al., 1997; Greenham et al., 1997; Huynh et al., 1999; Huynh et al., 2002; Mattoussi et al., 1999; Zenkevich et al., 2007) or inorganic glasses (Darbandi et al., 2005; Eisler et al., 2002) for the protection from environmental degradation or for added functionality and/or device applications. For biological and medical applications the main attempt related to performing hydrophilic capping of core/shell QDs and to prevent their precipitation.

Typically, the QDs synthesized in organic solvents have hydrophobic surface ligands such as trioctylphosphine oxide (TOPO), trioctylphosphine (TOP), tetradecylphosphonic acid (TDPA), or oleic acid (William et al., 2006). Two strategies have been applied to disperse QDs in aqueous buffers. The first method includes the exchange of the hydrophobic monolayer on the QD surface on the hydrophilic ligands. At the second method the native hydrophobic ligands can be retained on the QD surface. Additionally on the QD surface the adsorption of amphiphilic polymers, which includes hydrophilic segments such as polyethylene glycol (PEG) or multiple carboxylate groups, has been performed. A set of polymers have been reported, such as octylamine-modified polyacrylic acid (Yu et al., 2003), PEG-derivatized phospholipids (Dubertret et al., 2002), block copolymers (Gao et al., 2004), and amphiphilic polyanhydrides (Kirchner et al., 2005). The core/shell QDs are negatively charged if dihydrolipoic acid (DHLA) or octylamine-modified polyacrylic acid have been used as a surface-capping agent (Jaiswal et al., 2003; Wu et al., 2003). All these polymers provide relatively simple surface-modification of QDs for approaching biological compatibility.

Recently, the interest appears to the coating of emitting QDs with a layer of transparent silica (Chin 2004; Fogg et al., 1997; Greenham et al., 1997; Huynh et al., 1999; Huynh et al., 2002; Mattoussi et al., 1999; William et al., 2006; Zenkevich et al., 2007). Silica coating is expected to bring many advantages due to the thin silica layer (Fig. 2). A protective capping material on the QD surface increases the mechanical stability, enables a transfer into various organic and aqueous solvents, and protects QDs against oxidation and agglomeration; as well it improves the QD biocompatibility. Actually the surface of silica can be easily modified to link bioconjugators. 


\section{Optical properties of II-VI semiconductor core/shell QDs}

The high quality nanoscale CdSe crystals has allowed at the middle of $90^{\text {th }}$ of last century to resolve and study the QD size dependence of up to eight excited states in QD absorption spectra. This study was carried out for the strong confinement regime when the QDs are small compared to the exciton Bohr radius and absorption transitions are between discrete quantum size levels of electrons and holes in QDs (Efros et al., 1996; Norris et al., 1996). Let us consider absorption and photoluminescence spectra of CdSe QDs of different sizes presented in (Efros et al., 1996; Norris et al., 1996). The samples were prepared using the technique described in (Mural et al., 1993) and presented in n.2 of this chapter. Using this method nearly monodispersed wurtzite crystallites of CdSe $(\sigma \ll 5 \%)$ were prepared with the surface passivated by an organic tri- $n$-octylphosphine/tri- $n$-octylphosphine oxide ligands. The effective radii of studied QDs were determined in the range from 12 to $56 \AA$ using small angle X-ray scattering and TEM measurements (Efros et al., 1996). The samples were isolated and redispersed into a mixture of $o$-terphenyl in trinbutylphosphine $\sim 200 \mathrm{mg} / \mathrm{ml}$ to form an optically clear glass located between sapphire separated by a $0.5 \mathrm{~mm}$ thick Teflon.

Fig. 3 and Fig. 4 present the normalized absorption and full luminescence spectra for the set of CdSe QD's with radius between 12 and $56 \AA$, excited by a $300 \mathrm{~W}$ Xe arc lamp with broad beam ( $\sim 50 \mathrm{~nm}$ FWHM) to prevent the size selection of QDs (Efros et al., 1996; Norris et al., 1996).

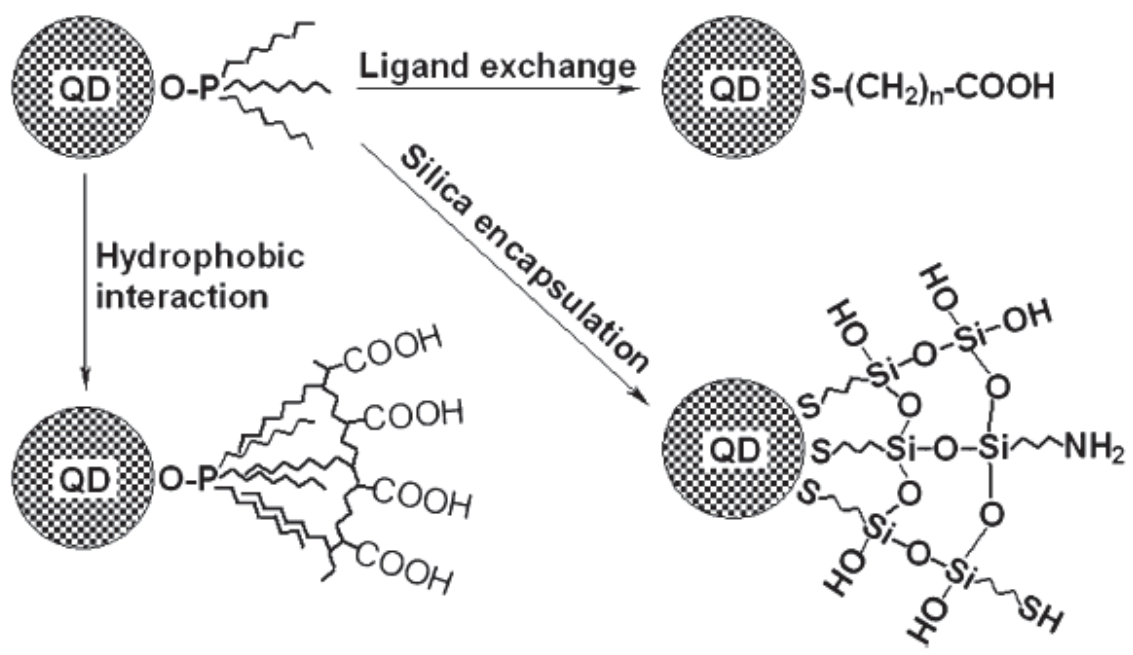

Fig. 2. Quantum dot (QD) water solubilization strategies (Parak et al., 2002).

It is clearly seen from figure 3 the shift of absorption and emission spectra into low energy side with the QD size increasing. The resulting full luminescence, excited at above QD bandedge absorption, contains contributions from all crystallites in the QD ensemble and is inhomogeneously broadened without distinct phonon structure. The full luminescence and absorption spectra show a strong size dependence of the Stokes shift, which varied from 100 meV for small QD sizes to $25 \mathrm{meV}$ for large QD sizes (Efros et al., 1996). The high energy excited states are clearly seen in QD absorption spectra as well. The comparison of theoretically predicted and experimentally detected results has shown that energy and 
transition dynamics of band-edge emission can be quantitatively understood in terms of the intrinsic band-edge exciton (Efros et al., 1996; Norris et al., 1996). The long lifetimes of the band-edge luminescence $(\sim 1 \mu \mathrm{s}$ at $10 \mathrm{~K})$ was attributed to the exciton thermalization to a dipole forbidden $+/-2$ dark exciton states.

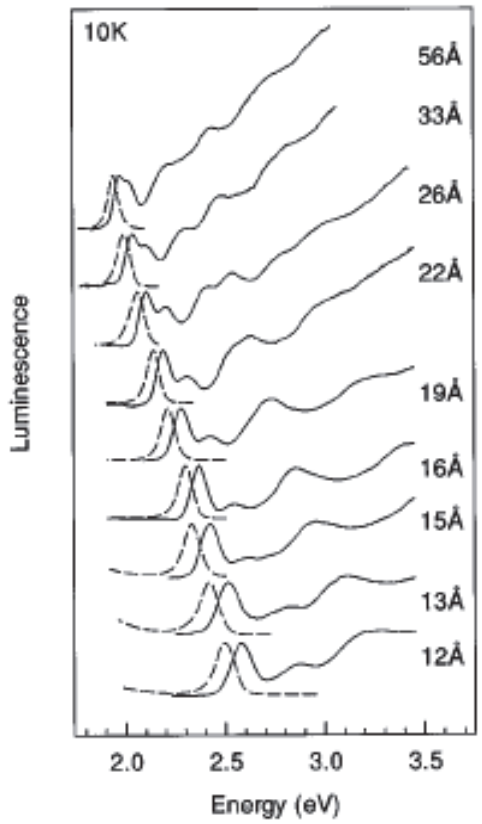

Fig. 3. Normalized absorption and full luminescence spectra for CdSe QD's between 12 and $56 \AA$ in radius. The absorption spectra are indicated by solid lines; the corresponding luminescence spectra by dotted lines. (Efros et al., 1996).

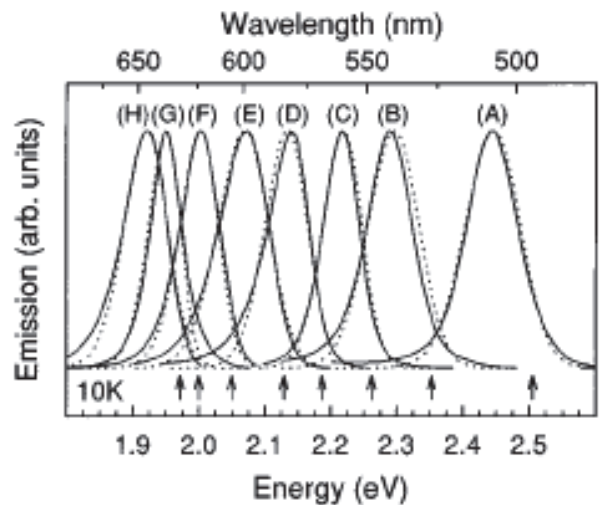

Fig. 4. Full luminescence spectra for QD size series from $15 \AA(A)$ to $50 \AA$ (H) (solid lines). Arrows indicate the PL excitation positions and dotted lines show the best fit obtained by the global fitting procedure (Norris et al., 1996). 
With the size control that can now be achieved for CdSe QDs, the capping of lower band-gap (CdSe, CdTe....) core nanocrystals with a higher band-gap (CdS, ZnSe, ZnS...) shells is an attractive possibility that leads to the core/shell QDs with improved luminescence, higher stability (protected from the surrounding environment), and perfect electrically connection (Korton et al., 1990, Hoener et al., 1992, Hines \& Guyot-Sionnest, 1996). In early 90th the CdSe nanocrystals have been successfully capped with ZnS (Kortan et al., 1990; Hines et al., 1996) and ZnSe (Hoener et al., 1992) for modification the surface passivation conditions. An advantage of $\mathrm{ZnS}$ shell in comparison with CdS shell is that $\mathrm{ZnS}$ forms at lower temperatures than CdS and ZnS and CdSe do not alloy well. The last aspect leads to the large lattice mismatch (12\%) between two materials CdSe/ZnS (Madelung, 1992). The ZnS-capped CdSe exhibited enhanced band-edge luminescence, and an order of magnitude increased the quantum yield (Kortan et al., 1990), as well as decreased the surface trap concentration detected for the CdSe-TOPO QDs in the 700-800 nm spectral range and a much reduced tendency to permanent bleaching (Hines et al., 1996; Gong et al., 2007).

With the growth of $\mathrm{ZnS}$ shell on the surface of CdSe core absorption and emission spectra changed ((Hines et al., 1996; Gong et al., 2007; Rakovich et al., 2003). Fig. 5 shows the variation of absorption and emission spectra of CdSe QDs with the core size of $4.0 \mathrm{~nm}$ as the thickness of ZnS shell increased from roughly 0.3 to $1.7 \mathrm{~nm}$ (Rakovich et al., 2003). It is clear that emission and first absorption peaks monotonically shift into low energy spectral range together with broadening of absorption peaks when the ZnS shell thickness enlarges (Rakovich et al., 2003). A red-shift of absorption and emission spectra upon passivation at the shell formation is explained by a weakening of the carrier confinement in CdSe QDs due to its partial tunneling into the ZnS shell (Dabbousi et al., 1997; Dzhagan et al., 2008). The red-shift is larger when the shell becomes thicker (Dzhagan et al., 2008). Comparable shifts in the optical spectra of $\mathrm{CdSe} / \mathrm{ZnS}$ and CdSe/CdS are obtained because of a weaker tunneling of the core-confined carriers into the shell made of a wider bandgap material (Dzhagan et al., 2008).

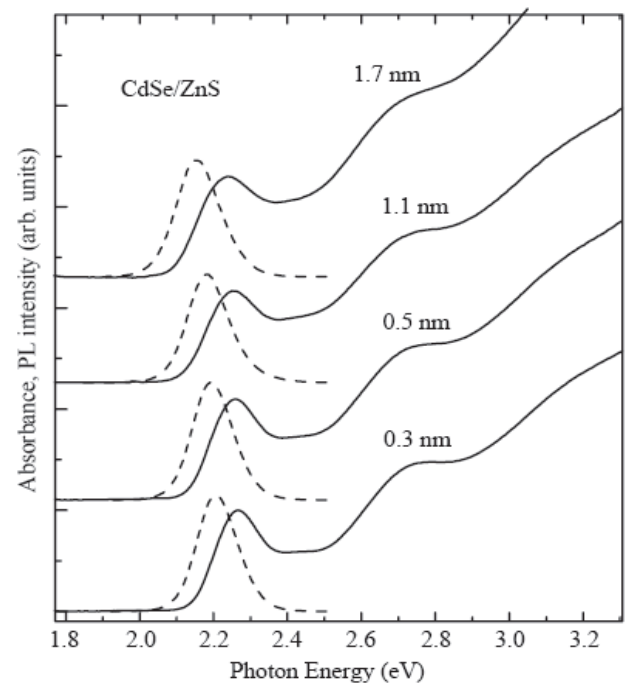

Fig. 5. Room-temperature absorption and emission spectra of CdSe nanocrystals with different thicknesses of ZnS shell (in nanometers. Rakovich et al., 2003). 
The Raman scattering in CdSe QDs has been studied efficiently during last two decades (Alivisatos et al., 1989; Baranov et al., 2003; Dzhagan et al., 2007; Dzhagan et al., 2008; Hwang et al., 1999; Meulenberg et al., 2004; Torchynska et al., 2007; Torchynska et al., 2008). The original CdSe QDs passivated by organic molecules reveal a Raman peak related to scattering by the longitudinal optical (LO) phonon at about 206-210 $\mathrm{cm}^{-1}$ (Meulenberg et al., 2004), which is red-shifted from its bulk value of $213 \mathrm{~cm}^{-1}$ due to phonon confinement (Meulenberg et al., 2004; Tanaka et al., 1992), as well as a weaker mode arising from the second order (2LO) appeared at $415 \mathrm{~cm}^{-1}$ (Meulenberg et al., 2004). The shift of a LO phonon Raman peak from 210 $\mathrm{cm}^{-1}$ down to $205 \mathrm{~cm}^{-1}$ and LO Raman peak softening with decreasing QD sizes from $3.0 \mathrm{~nm}$ to $1.6 \mathrm{~nm}$ was theoretically predicted in (Meulenberg et al., 2004). But the different sample passivation produces a different magnitude of LO phonon shift suggesting a variance in the nature of the phonon confinement with passivant type and/or the strain effects due to effective compressive or tensile surface stresses in QDs (Meulenberg et al., 2004).

The effect of ZnS shell thickness in the range 1.0-3.5 ML on the phonon spectra in CdSe QDs was studied in (Baranov et al., 2003). The Raman lines of LO and 2LO phonons of the CdSe core and the line of LO phonons of the $\mathrm{ZnS}$ shell at about $350 \mathrm{~cm}^{-1}$ with intensity comparable to that of 2LO CdSe peak are clearly seen in the Raman spectrum (Fig. 6). It is shown that the line of ZnS LO phonons at $350 \mathrm{~cm}^{-1}$ partly overlaps the second order Raman lines of the CdSe core, but it can be distinguished even at the ZnS shell thickness of 0.5 ML.

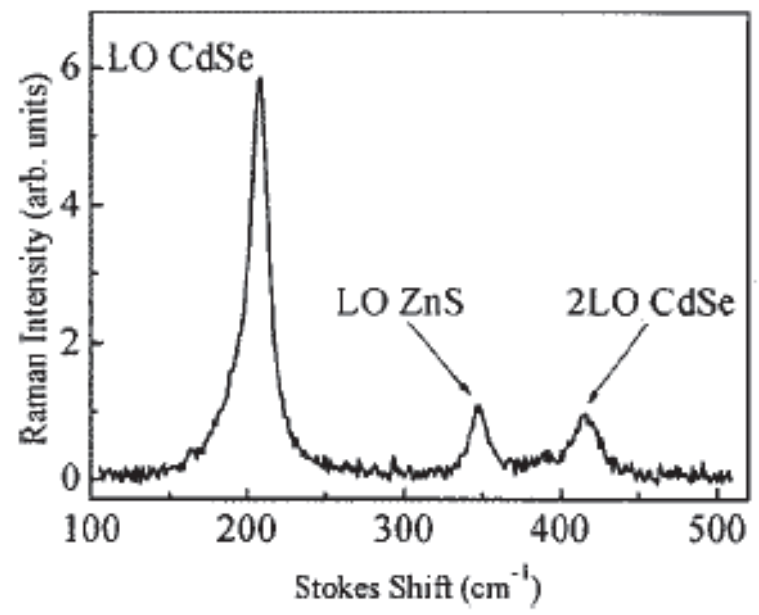

Fig. 6. Raman spectrum of CdSe/ZnS QD's with a shell thickness 3.4 ML excited by a 476.5$\mathrm{nm}$ line of an Ar laser (Baranov et al., 2003).

The Raman spectrum transformation in dependence on the shell types (CdS, ZnS) and the order of shell atom deposition: CdSe/ZnS1 (Zn then S), CdSe/ZnS2 (S then Zn) or CdSe/CdS2 (S then Cd) were studied in (Baranov et al., 2003; Dzhagan et al., 2007). After passivation with CdS the LO phonon Raman peak at $206 \mathrm{~cm}^{-1}$ and an additional Raman peak around $270 \mathrm{~cm}^{-1}$ have been revealed (Fig. 7). The Raman peak at $270 \mathrm{~cm}^{-1}$ was assigned to Cd-S vibrations in the shell (Dzhagan et al., 2008). The phonon confinement and lattice mismatch-induced strain can induce the shift of LO phonon Raman lines in thin-layer 
superlattices and in core/shell QDs by more than $20 \mathrm{~cm}^{-1}$ (Dinger et al., 1999). The authors supposed that the Cd-S vibration related Raman peak appeared at $270 \mathrm{~cm}^{-1}$, which downward shifted on $30 \mathrm{~cm}^{-1}$ from the bulk value of the CdS LO phonon, $305 \mathrm{~cm}^{-1}$, due to the formation of an alloyed layer at the interface between CdSe core and CdS shell.

The interdiffusion during the ZnS shell growth was also assumed for CdSe/ZnS QDs, which revealed a similar Cd-S mode (Dzhagan et al., 2008). The role of sulfur as an initiator of the interdiffusion was supported by the fact that the CdS-like peak was observed to be stronger (Fig.7) for the samples where sulfur atoms were deposited first (CdSe/ZnS2). The larger lattice mismatch for the CdSe/ZnS interface can further stimulate interdiffusion. The red shift of the CdSe LO phonon peak after passivation (Fig. 7) was explained by the formation of an intermixed core/shell interface as well. The late effect is accompanied by the quenching of QD emission intensity.

\section{Theoretical analysis of the emission spectra of QDs using mirror boundary conditions in the quantum mechanical description}

To explain the emission spectra of QDs observed, the corresponding system of electronic energy levels for them should be known. Theoretical analysis of the energy spectra and optical properties of nanosized semicoinductor sphere was published first in 1982 (Efros \& Efros, 1982), and the discussed core-shell II-VI semiconductor QDs present ideal material for comparison of theory with experiment.

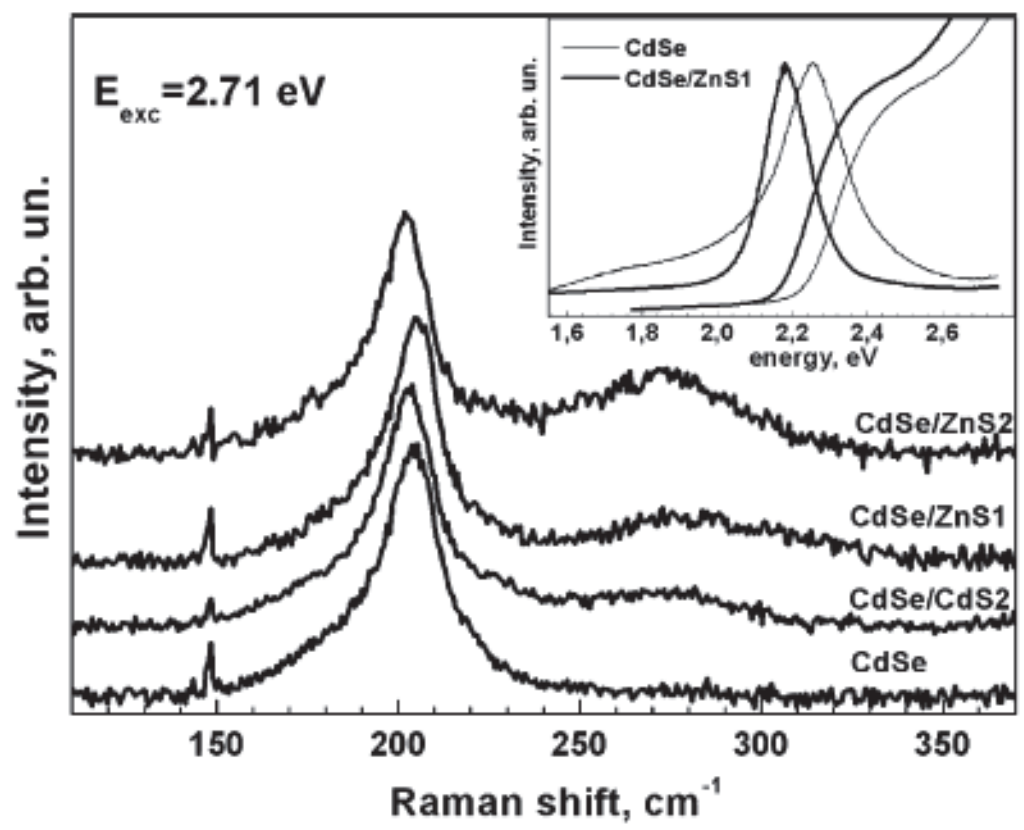

Fig. 7. Normalized Raman spectra of CdSe and core-shell QDs. Inset: Absorption and PL of CdSe and CdSe/ZnS QDs (Dzhagan et al., 2008). 
However, during almost two decades of investigation of these objects, no one publication appeared related to such a comparison. As we shall see, the reason for that is simple: the calculations performed in (Efros \& Efros, 1982; Gaponenko, 1998) predict much larger energy levels separations than those observed experimentally. We attribute this discrepancy to the boundary conditions used for description of a spherical QDs in all previous publications: namely, the traditional "impenetrable walls" boundary conditions. Another point is that the effective mass approximation normally used in these calculations, could be questioned in case of nanosized semiconductor particles. We have shown that both the agreement of theory with experiment and the applicability of the effective mass approximation could be greatly improved using another type of boundary conditions, as we call them, even mirror boundary conditions. We assume that a particle (electron) confined in a QD is specularly reflected by its walls; the assumption is based on the data of STM (Schmid et al., 2000) showing a clear interference pattern near the surface of a solid created by incident and reflected de-Broglie waves for an electron; an attempt to treat walls of a quantum system as mirrors was made previously (Liboff and Greenberd, 2001; Liboff, 1994) in so-called "quantum billiard" problem; however, the analytical form of the conditions employed in these papers was different from ours and much more complicated.

In our treatment of QD boundary as a mirror, the boundary condition will equalize values of particle's $\Psi$-function in an arbitrary point inside the QD and the corresponding image point in respect of mirror-reflective wall. In a general case, one can allow $\Psi$-functions to coincide by their absolute value, since the physical meaning of the wave function is connected to $\Psi^{*} \Psi$. Thus, depending on the sign of the equated values of $\Psi$, one will obtain even and odd mirror boundary conditions. For the case of odd boundary condition incident and reflected waves cancel each other at the boundary, so that one will obtain the case equivalent to that of impenetrable walls with zero $\Psi$-function at the boundary, representing "strong" confinement case. However, experimental data (Dabbousi et al., 1997) show that it is not always so - there is a possibility that a particle may penetrate the barrier, and then return again into the confined volume. Thus, the wave function will not vanish at the boundary, and the system will be considered as a "weak" confinement as long as particle flux through the boundary is absent (Liboff, 1994).

Application of the new boundary conditions for such weak confinement case will yield solution different from those for QD with impenetrable boundaries. Supposedly, the resulting energy spectrum would be also different, which may offer better explanation of some experimental data. Therefore, here the treatment is focused on weak confinement case with even mirror boundary conditions, which is a timely and very important task that, to our point of view, will be important for bringing theory and experiment together. In the considered quantum dot with mirror-reflective boundaries, as a particle (electron, hole) is approaching the wall from inside, its image will also do so from the outside, meeting with the particle at the boundary. Due to the specular reflection, the actual particle continues to move along the trajectory of its image inside the QD whereas the image keeps on moving outside, virtually expanding a QD into a lattice of reflected cells. Formation of such virtual periodic structure extension greatly favours the effective mass approximation. Thus, to investigate the specific features of the problem, we consider only the even form of mirror boundary conditions here. Assuming the potential inside the quantum box (QD) equal to zero and using the common variable separation method, we look for a solution of the stationary Schrödinger equation $\Delta \Psi+\mathrm{k}^{2} \Psi=0$ (with $\mathrm{k}^{2}=2 \mathrm{mE} / \hbar^{2}$ and particle mass $\mathrm{m}$ ) in the form 


$$
\Psi=\prod_{j} \Psi_{j}\left(x_{j}\right)=\prod_{j}\left(A_{j} \exp \left(i k_{j} x_{j}\right)+B_{j} \exp \left(-i k_{j} x_{j}\right)\right) .
$$

Here $x_{j}$ describe the coordinates $x, y, z$ and $k_{j}$ - the components of wave vector $\mathbf{k}$. For our case of a spherical QD, following the treatment made in (Efros \& Efros, 1982; Gaponenko, 1998) we apply the common methodology of a particle confined in a three-dimensional square well potential (for example, Schiff, 1968). The wave function in polar coordinates has a form

$$
\Psi(\mathrm{r}, \theta, \varphi)=\mathrm{R}(\mathrm{r}) \mathrm{Y}_{\mathrm{l}, \mathrm{m}}(\theta, \varphi)
$$

The angular part $\mathrm{Y}_{1, \mathrm{~m}}$ is similar to that of hydrogen atom. The energy spectrum is determined by solution of the radial part of equation $R(r)$, which is expressed in spherical Bessel functions of half-odd-integer order for the new variable $\rho=\alpha$ r; for our purposes it will be sufficient to analyze the first of them

$$
\mathrm{j}_{0}(\rho)=\sin \rho / \rho
$$

with $\rho / r=\alpha=\hbar^{-1}(2 m E)^{1 / 2}$.

For the case of the impenetrable walls of a QD, the boundary condition is $\sin \alpha r=0$ (for sphere radius $\mathrm{r}=a / 2$ and diameter $a$ ). Thus, one will have $\alpha \mathrm{a} / 2=\pi \mathrm{n}$ yielding the energy spectrum (in agreement with (Efros \& Efros, 1982; Gaponenko, 1998))

$$
E=\frac{h^{2}}{2 m a^{2}} n^{2}=\frac{h^{2}}{8 m a^{2}}(2 n)^{2}, n=1,2,3, \ldots
$$

Here $m$ is the effective mass of a particle confined in a QD. As one can see, the parameter $\alpha$ has the meaning of a wave vector, i.e. if we introduce de-Broglie wavelength $\lambda$, then $\alpha=$ $2 \pi / \lambda$. The condition obtained $a=\mathrm{n} \lambda$ requires an integer number of wavelengths fit along the diameter of the sphere.

To introduce the mirror boundary condition, we employ the spherical reflection laws to find the position " $\mathrm{x}$ " of the reflected image of the point characterized with a radius vector " $\mathrm{r}$ " nearby the wall, so that $x=0$ and $r=0$ will correspond to the centre of a sphere. For the standard expression for spherical mirror

$$
(\mathrm{r}-a / 2)^{-1}+(\mathrm{x}-a / 2)^{-1}=-4 / a .
$$

so that

$$
\mathrm{x}=a \mathrm{r} /(4 \mathrm{r}-a)
$$

If the particle given by $\mathrm{r}$-value locates in direct vicinity of quantum dot wall, one should set $\mathrm{r}=a / 2-\delta$ having $\delta<a / 2$. In this case $\mathrm{x} \approx a / 2+\delta$, meaning that at negligibly small distances between the mirror and the object, a spherical mirror behaves similarly to the planar one. Under these assumptions, the mirror boundary condition will have the form

$$
\Psi(\alpha / 2-\delta, \theta, \varphi)=\Psi(\alpha / 2+\delta, \theta, \varphi)
$$

Using spherical Bessel functions for the radial eigen-function, we obtain from (5) the condition $\cos \alpha a / 2=0$, which gives $\alpha a / 2=\pi(2 \mathrm{n}+1) / 2$, and the energy spectrum

$$
E=\frac{h^{2}}{8 m a^{2}}(2 n+1)^{2}, n=0,1,2, \ldots
$$


As one can see, now the diameter of the sphere can include only odd number of halfwavelengths. This expression is different from the previous one: in (4) we have the coefficient $h^{2} / 8 m a^{2}$ multiplied by squares of even integers, whereas (6) feature the squares of odd integers only. For large quantum numbers this difference is not essential, but for small " $\mathrm{n}$ " it is pronounced, reaching $400 \%$ for the lowest energy state.

Since the form of the energy spectra obtained with mirror boundary conditions does not differ from that obtained with traditional methodology, we will use the classification of quantum confinement types for a spherical QDs employed in (Efros \& Efros, 1982; Gaponenko, 1998) and discuss only the strong confinement case with $a / 2<<a_{\mathrm{B}}$, where $a_{\mathrm{B}}$ is the Bohr radius for an exciton:

$$
a_{B}=\frac{\hbar^{2} \varepsilon}{\mu e^{2}}
$$

with reduced mass $\mu=\left(m_{e} m_{h}\right) /\left(m_{e}+m_{h}\right)$, electron and hole masses $m_{\mathrm{e}, \mathrm{h}}$ and dielectric constant of the material $\varepsilon$. Following the argumentation of (Efros \& Efros, 1982; Gaponenko, 1998), the current case can be considered as a simplification when one can use the expressions for energy spectra obtained $(4,6)$ with the corresponding effective mass $m$. The reason for that is that the separation between the quantum levels is of the order $\hbar^{2} / m a^{2}$, which is large compared to the Coulomb interaction energy between an electron and a hole that is proportional to $e^{2} / \varepsilon a$. Therefore, we can ignore the Coulomb interaction, taking only the aforementioned energy spectra expressions for the case of quantum confinement effect. According to (Efros \& Efros, 1982; Gaponenko, 1998), the optical absorption threshold for the spherical semiconductor QD is given by the expression

$$
\hbar \omega_{01}=E_{g}+\frac{h^{2}}{2 \mu a^{2}}
$$

which corresponds to the spectrum (4) with $n=1$ for the case of impenetrable walls. For the spherical quantum well with mirror-reflecting walls we use the expression (6), which for the optical absorption threshold $(\mathrm{n}=0)$ will yield:

$$
\hbar \omega_{01}=E_{g}+\frac{h^{2}}{8 \mu a^{2}}
$$

Among the great amount of papers devoted to various QDs, not many present the experimental values of energy levels together with the exact well dimensions. Luckily, such data can be found for $\mathrm{CdSe} / \mathrm{ZnS}$ core-shell quantum dots. They are pronouncedly spherical, with exactly known dimensions and positions of the lower energy levels.

We assume that in these core-shell QDs the carrier reflections conditions are fulfilled at the $\mathrm{CdSe} / \mathrm{ZnS}$ boundary, as discontinuity of electrical potential causes reflection of the particle flux. Thus, one can safely hypothesize the walls of CdSe quantum well could be considered as effective mirror surface confining the particles.

To compare the experimental data with the theory, we use the following parameters of CdSe (Gaponenko, 1998; Haus et al., 1993): $m_{\mathrm{e}} / m_{\mathrm{o}}=0.13, m_{\mathrm{h}} / m_{\mathrm{o}}=0.45\left(m_{\mathrm{o}}\right.$ - the free electron mass), material dielectric constant around 10. For the band gap, we take recently found value of $E_{g}=1.88 \mathrm{eV}$ (Esparsa-Ponce et al., 2009) (while the previous value of $1.84 \mathrm{eV}$ (Gaponenko, 
1998; Haus et al., 1993) is also not much different). The reduced mass corresponding to the effective masses cited is $\mu=0.1 m_{0}$, resulting in the Bohr radius for the exciton to be about 5.3 $\mathrm{nm}$. The spherical nanocrystals of CdSe described above featured radii between 1.15 and $2.75 \mathrm{~nm}$, keeping the strong confinement condition valid for all the cases considered.

The Table 1 below summarizes the experimental data on spherical QDs of CdSe together with the calculated data. The absorption threshold wavelength $\lambda_{01}$ for nanocrystals with diameter $a=2.85 \mathrm{~nm}$ was taken from (Hines \& Guyot-Sionnest, 1996), the rest of the experimental data proceed from (Dabbousi, 1997). The photon energy $\hbar \omega_{01}$ corresponds to the absorption threshold, which differs by the energy difference $\Delta E$ from the band gap (i.e., supplying the degree of an actual quantum confinement effect). The values of $\Delta E_{\text {calc }}=\hbar \omega_{01}-E_{g}$ were calculated after expression (8) for QD with mirror-reflecting walls.

\begin{tabular}{|c|c|c|c|c|c|}
\hline$a, \mathrm{~nm}$ & 2.3 & 2.85 & 4.2 & 4.8 & 5.5 \\
\hline$\lambda_{01}, \mathrm{~nm}$ & 470 & 515 & 555 & 582 & 612 \\
\hline$\hbar \omega_{01}, \mathrm{eV}$ & 2.64 & 2.41 & 2.24 & 2.13 & 2.1 \\
\hline$\Delta E, \mathrm{eV}$ & $\mathbf{0 . 7 6}$ & $\mathbf{0 . 5 3}$ & $\mathbf{0 . 3 6}$ & $\mathbf{0 . 2 5}$ & $\mathbf{0 . 2 2}$ \\
\hline$\Delta E_{\text {calc, }} \mathrm{eV}(8)$ & $\mathbf{0 . 7 2}$ & $\mathbf{0 . 4 7}$ & $\mathbf{0 . 2 2}$ & $\mathbf{0 . 1 7}$ & $\mathbf{0 . 1 3}$ \\
\hline
\end{tabular}

Table 1. Comparison of theoretical and experimental data on light absorption in CdSe nanocrystals

As one can see, the energy values calculated using the expression (8) obtained for mirrorreflecting walls of a quantum well yields very good correlation with the experimental data, while the expression (7) obtained for the case of traditional impenetrable wall case gives the values about 4 times larger.

In Fig. 8 we present a data set for CdSe nanocrystals taken from (Invitrogen, 2010), showing the dependence of emitted photon energy upon well diameter $a$ (curve 1). Curve 2 corresponds to the energy (8), displaying a good agreement with the experimental data.

In our previous publications we have shown that the mirror boundary conditions could be successfully applied to other geometries of QDs, such as hexagonal, triangular and pyramidal (Vorobiev et al., 2009; Vorobiev et al., 2010; Vorobiev et al., 2011).

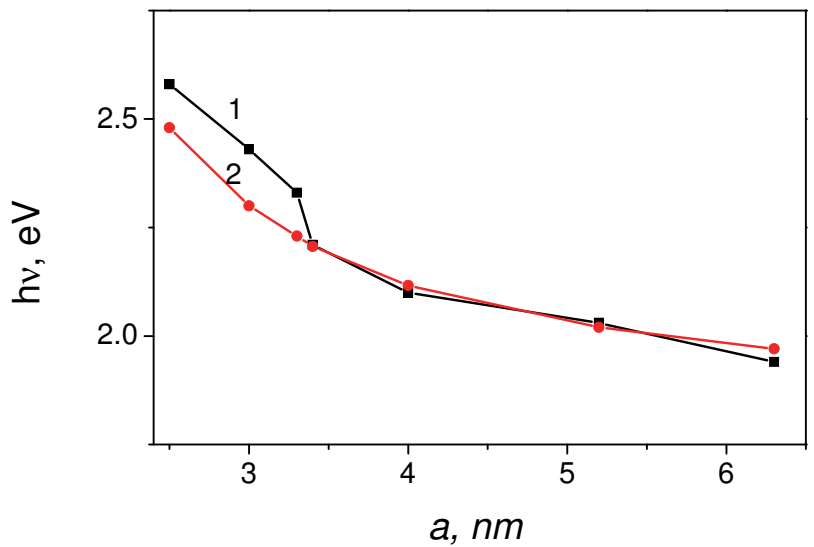

Fig. 8. Experimental (1) and calculated (2) exciton energy in CdSe QDs. 
Thus we can conclude that the method used can be considered as a simple and reliable approach for solution of the Schrödinger equation describing the particles confined in the semiconductor quantum dots, in particular, for the framework of effective mass approximation. Our theoretical predictions feature very good agreement with the experimental data for the spherical CdSe nanocrystals, while the traditional impenetrable wall approximation yields much overestimated results. The mirror boundary conditions are easy to implement, which allows simplifying consideration of a large variety of QD geometries and obtaining analytical expressions for the energy spectra for the different types of nanosystems.

\section{The process of QD bioconjugation for imaging, labelling and sensing}

As we mentioned above in n.2, the preparation of water-soluble II-VI core/shell QDs is an important step for many biological applications. QDs, as a rule, can be grown easily in hydrophobic inorganic solvents (see n.2). Then the methods of solubilisation are applied based mainly on exchange of the technological hydrophobic surfactant layer with a hydrophilic one (Bruchez et al., 1998; Gerion et al., 2001; Kim et al., 2003), or the preparation of a second surface QD layer by the adsorption of bifunctional linker molecules, which provide both hydrophilic character and functional groups for bioconjugation. In second method the layers are used, such as: the amphiphilic molecule cyclodextrin (Pellegrino et al., 2004), chitosan, a natural polymer with one amino group and two hydroxyl groups (Calvo et al., 1997; Miyzaki et al., 1990), PEG-derivatized phospholipids, encapsulation in phospholipid micelles (Dubertret et al., 2002), addition of dithiothreitol (Pathak et al., 2001), organic dendron (Guo et al., 2003; Wang et al., 2002), oligomeric ligands (Kim et al., 2003), or poly (maleicanhydride alt-1-tetradecene), as well as silica and mercaptopropionic acid (MPA) (Bruchez et al., 1998; Gerion et al., 2001). MPA achieves the conjugation through carboxyl groups, and silica through thiol groups on its surface. It is essential that, for example, phospholipid and block copolymer coatings tend to increase the diameter of CdSe-ZnS QDs from $\sim 4-8 \mathrm{~nm}$ before encapsulation to $\sim 20-30 \mathrm{~nm}$ (Chan et al., 1998; Medintz et al., 2005). Fig. 9 presents the schemes widely used for conjugation of proteins to QDs (Medintz et al., 2005).

The numbers of steps were used for preparing QDs to bioconjugation: the mixture of QDs during some time with the bifunctional linker in solution, the extraction from the organic solvent by centrifugation and re-dissolving QDs in an appropriate conjugation buffer (Chan et al., 1998). This algorithm was used initially for such linker molecules as: mercaptoacetic acid, glutathione and histidine, mercaptosuccinic acid, dithiothreitol, and for bifunctional compounds containing sulfhydryl groups (Aldana et al., 2001; Pathak et al., 2001). The disadvantage of this procedure is the slow desorption of linker molecules that causes the QD precipitation and long-term storage problems (Jamieson et al., 2007; Mattoussi et al., 2000). To improve the long-term stability of biocompatible QDs a set of methods has been proposed, such as (Jamieson et al., 2007): (a) the use of engineered recombinant proteins joint electrostatically to a QD surface which were modified with dihydrolipoic acid, (b) the use of hydrophilic organic dendron ligands to create a hydrophilic shell of QDs, (c) the application of a micellar encapsulation procedure in which phospholipid molecules surround the TOPO coated QD surface, and (d) the conjugation of QDs to streptavidin via an amphiphilic polymer coating. The steady improvement in producing of biocompatible IIVI QDs made over the past 10 years has contributed essentially to the successful implementation of these new luminescent markers in biology and medicine. 
a Bifunctional linkage

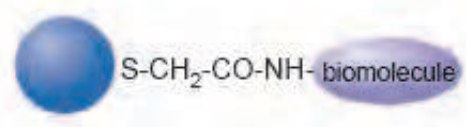

b Hydrophobic attraction

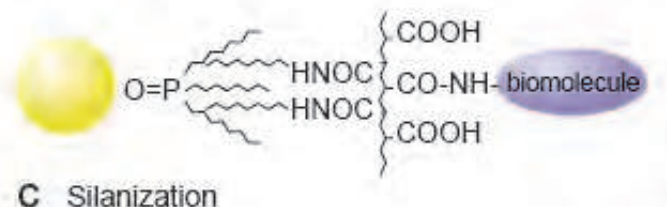

C Silanization

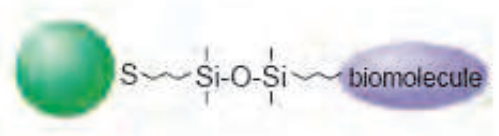

\section{d Electrostatic attraction}

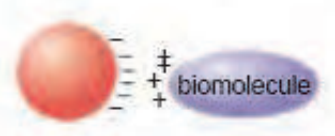

e Nanobeads

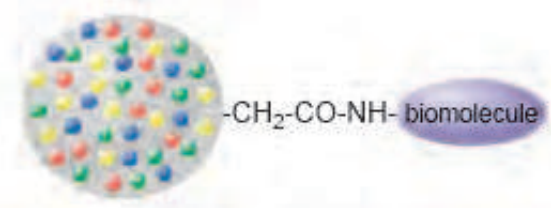

Fig. 9. A schematic presentation of different approaches of QD conjugation to biomolecules (Jamieson et al., 2007; Medintz et al., 2005): (a) Use of a bifunctional ligand such as mercaptoacetic acid for linking QDs to biomolecules. (b) TOPO-capped QDs bound to a modified acrylic acid polymer by hydrophobic forces. (c) QD solubilisation and bioconjugation using a mercaptosilane compound. (d) Positively charged biomolecules linked to negatively charged QDs by electrostatic attraction. (e) Incorporation of QDs into microbeads and nanobeads.

\section{PL spectra of nonconjugated core/shell CdSe/ZnS QDs with interface states}

The ability to cover core/shell II-VI QDs with polymers and biomolecules is a critical step, as we mentioned above, in producing efficient bio-luminescent markers. We have shown early (Torchynska et al., 2009 a, b and c) that core/shell CdSe/ZnS QDs with radiative interface state are very promising for the spectroscopic confirmation of the bioconjugation process. These systems permit to detect both the variation of PL intensity at the bioconjugation, that ordinary has been monitored, and the transformation of emission spectra related to the change of a full width at half maximum (FWHM) (Torchynska b and c; Vega Macotela et al., 2010a) and PL peak positions, as well as the transformation of Raman scattering spectra (Torchynska et al., 2007; Torchynska et al., 2008; Vega Macotela, 2010b; Diaz-Cano et al., 2010).

The nature of radiative interface states in the core /shell CdSe/ZnS QDs has to be investigated. To study the origin of interface states, the PL spectra of CdSe/ZnS QDs covered by the amine-derivatized PEG polymer with core emission at 525, 565, 605 and 640 $\mathrm{nm}$ have been investigated in dependence on the size of CdSe cores. Then PL spectra of 565 and $605 \mathrm{~nm}$ QDs have been studied in dependence on a set of factors, such as: i) the size of CdSe cores, ii) the temperature of PL measurements (10 and $300 \mathrm{~K})$, iii) the state of bioconjugation and iv) the time of aging in ambient air. 
Commercially available core-shell CdSe/ZnS QDs, covered with amine-derivatized polyethylene glycol (PEG) polymer, are used in a form of colloidal particles diluted in a phosphate buffer (PBS) with a 1:200 volumetric ratio. Studied QDs are characterized by the sizes: i) 3.2-3.3 $\mathrm{nm}$ with color emission at $525-530 \mathrm{~nm}(2.34-2.36 \mathrm{eV})$, ii) $3.6-4.0 \mathrm{~nm}$ with color emission at 560-565 nm (2.19-2.25 eV), ii) 5.2-5.3 nm with emission at 605-610 nm (2.03-2.08 eV) and iv) 6.3-6.4 $\mathrm{nm}$ with color emission at 640-645 $\mathrm{nm}(1.92-1.94 \mathrm{eV})$. Some parts of CdSe/ZnS QDs (named 565P and 605P) were bioconjugated that we will discuss in next section. Other parts of CdSe/ZnS QDs (named 525N, 565N, 605N and 640N) have been left nonconjugated and serve as a reference object. Nonconjugated CdSe/ZnS QDs in the form of a $5 \mathrm{~mm}$ size spot were dried on a polished surface of crystalline Si substrates as described earlier in (Torchynska et al., 2009 a, b and c; Vega Macotela et al., 2010a). PL spectra were measured at $300 \mathrm{~K}$ and some of them at $10 \mathrm{~K}$ at the excitation by a He-Cd laser with a wavelength of $325 \mathrm{~nm}$ and a beam power of $20 \mathrm{~mW}$ using a PL setup described in (Torchynska et al., 2009 a, b and c; Vega Macotela et al., 2010a).

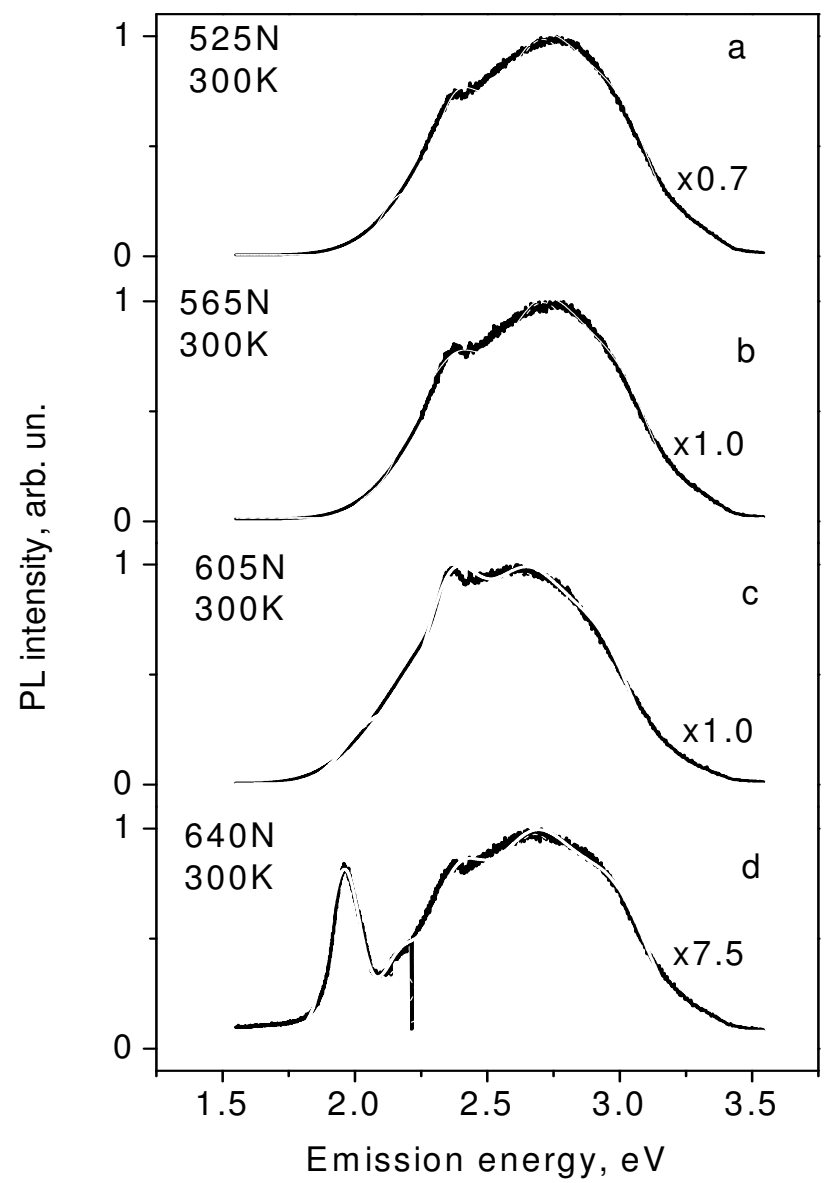

Fig. 10. CdSe/ZnS QDs of different sizes with interface states 
Normalized PL spectra of nonconjugated CdSe/ZnS QDs measured at $300 \mathrm{~K}$ demonstrate the broad PL band in the spectral range of $1.80-3.20 \mathrm{eV}$ with a main maximum at $2.37 \mathrm{eV}$ and with shoulders (or small peaks) (Fig. 10). This broad PL band does not depend on the size of CdSe QD cores (Fig. 10). It is clear that the broad PL bands are a superposition of elementary PL bands. The deconvolution procedure has been applied to PL spectra permitting to represent them as a superposition of five elementary PL bands (Fig. 11a,b). The peaks of elementary PL bands are at 2.02, 2.17, 2.33, 2.64 and $3.03 \mathrm{eV}$ (Fig. 11a) for 605N QDs and at $1.99,2.19,2.35,2.64$ and $3.03 \mathrm{eV}$ (Fig. 11b) for 565N QDs. PL bands with the peaks at $2.02 \mathrm{eV}$ $(605 \mathrm{~N})$ and $2.19 \mathrm{eV}(565 \mathrm{~N})$ relate to emission of ground state excitons in the CdSe cores of corresponding QDs. The nature of other PL bands needs to be studied.

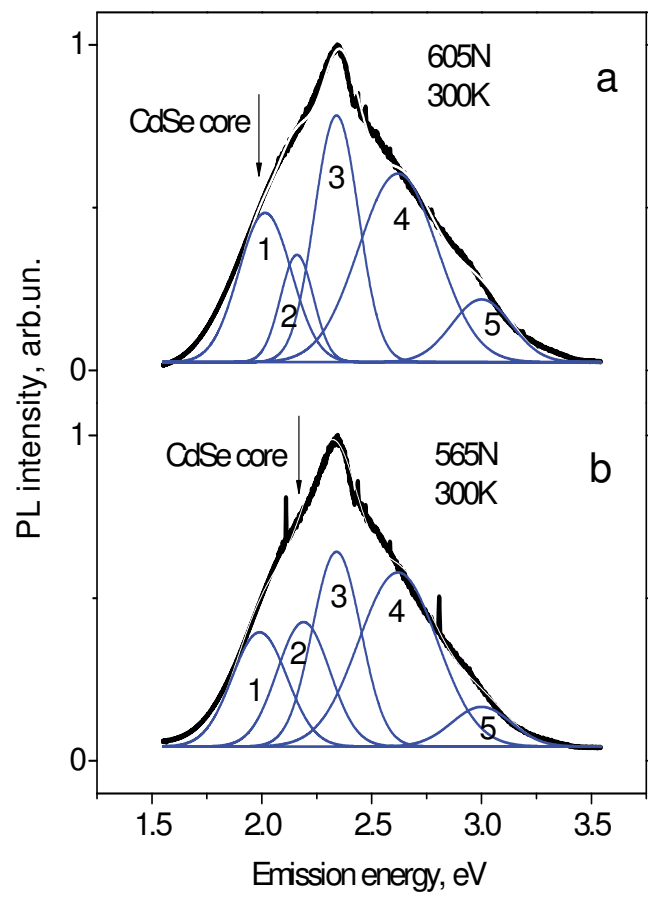

Fig. 11. The deconvolution results for 605N QDs (a) and 565N QDs (b)

The high energy PL bands can be assigned to the electron-hole recombination via: i) excited states in the CdSe core ii) defects in the CdSe core or ZnS shell and/or iii) interface states at the $\mathrm{ZnS} /$ polymer interface. The PL spectrum of nonconjugated $(605 \mathrm{~N}) \mathrm{CdSe} / \mathrm{ZnS}$ QDs has been studied at a low temperature $(10 \mathrm{~K})$ with the aim to clarify the nature of high energy PL bands (Fig. 12). As one can see in Fig. 12 the PL spectrum does not change essentially at temperature decreasing. The result of deconvolution has shown that only the PL band related to a CdSe core shifts from $2.02 \mathrm{eV}(300 \mathrm{~K})$ up to $2.12 \mathrm{eV}(10 \mathrm{~K})$ due to increasing the optical band gap in a CdSe core at $10 \mathrm{~K}$. The temperature variation of CdSe core peak energy was found to be $2.210^{-4} \mathrm{eV} / \mathrm{K}$ that is less than the value obtained earlier $\left(3.310^{-4} \mathrm{eV} / \mathrm{K}\right)$ for the CdSe/ZnS QDs (Rusakov et al., 2003) with the thickness of $\mathrm{ZnS}$ shell from the range of 0.3-1.7 nm. The last fact is related, apparently, to the higher thickness of ZnS shell $(2 \mathrm{~nm})$ in studied CdSe/ZnS QDs 
(Invitrogen, 2010). Simultaneously the high energy PL bands do not change their spectral positions that testify that high energy PL bands are not connected with the defect-related states or excited states in semiconductors (CdSe or ZnS). Thus high energy PL bands can be assigned to the currier recombination via the interface states at the $\mathrm{ZnS} /$ polymer interface.

The permanent position of high energy PL bands in QDs with different CdSe core sizes (Fig. 10, Fig. 11), the independence of their PL peaks versus temperatures (10 K or $300 \mathrm{~K})$ (Fig. 12) permit to assign the high energy PL bands to the radiative recombination of photogenerated carriers via interface states related to the $\mathrm{ZnS} /$ polymer interface.

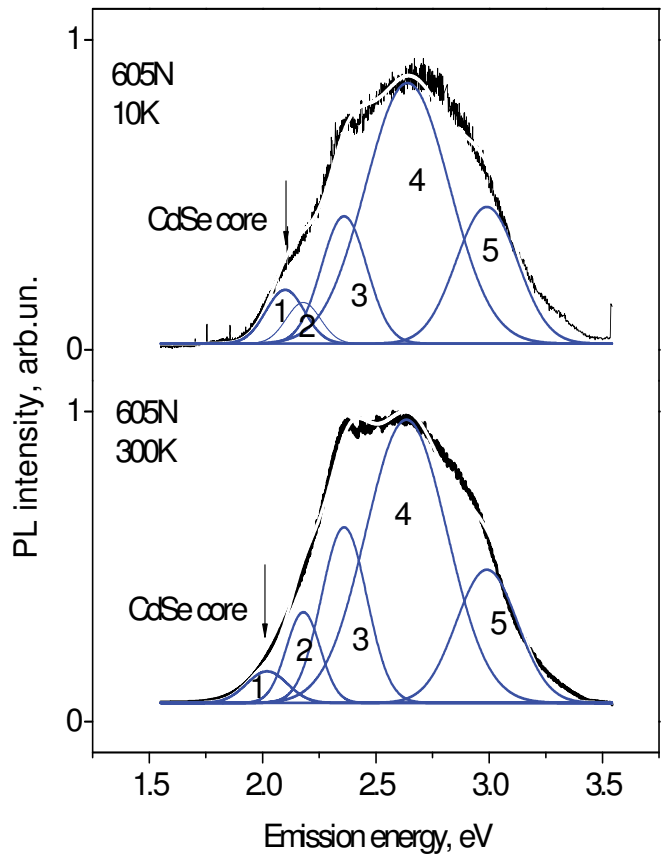

Fig. 12. PL spectra of $605 \mathrm{~N}$ QDs measured at the temperature of $10 \mathrm{~K}(\mathrm{a})$ and $300 \mathrm{~K}$ (b).

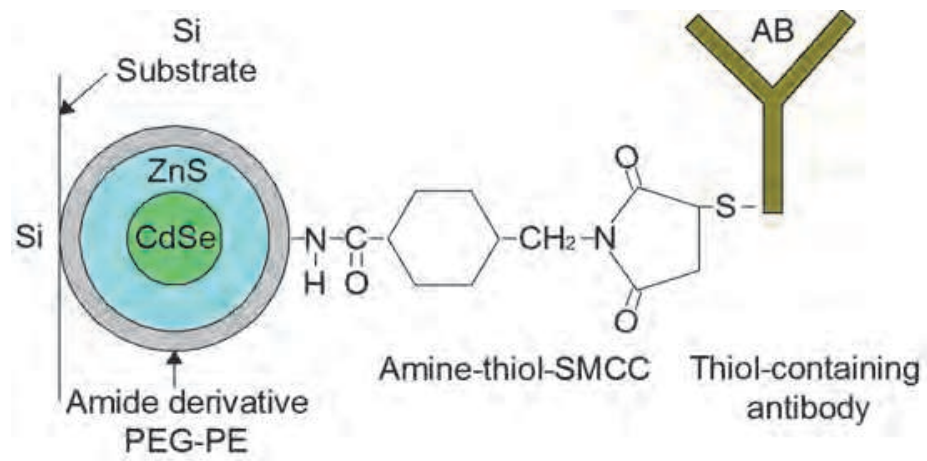

Fig. 13. The core/shell CdSe/ZnS QD system and the bioconjugation scheme. 


\section{The PL spectra of bioconjugated core/shell CdSe/ZnS QDs with interface states}

The part of $565 \mathrm{~nm}$ CdSe/ZnS QDs has been bioconjugated (named 565P) to the mouse anti PSA (Prostate-Specific Antigen) antibodies, mAb Z009, Ms IgG2a. The part of $605 \mathrm{~nm}$ QDs has been bioconjugated (605P) to the anti IL10 (Interleukin 10) antibodies, rat IgG2a, clone JES3-12G8, code MCA2250. At the bioconjugation the commercially available $565 \mathrm{~nm}$ and $605 \mathrm{~nm}$ QD conjugation kits have been used (Invitrogen, 2010). This kit contains aminederivatized PEG polymer coated QDs and the amine-thiol crosslinker SMCC. The conjugation reaction is based on the efficient coupling of thiols that present in reduced antibodies, to reactive maleimide groups which exist on the QD surface after the SMCC activation (Fig. 13). Bioconjugated CdSe/ZnS QDs in the form of a $5 \mathrm{~mm}$ size spot were dried on a polished surface of crystalline Si substrates (Fig. 13).
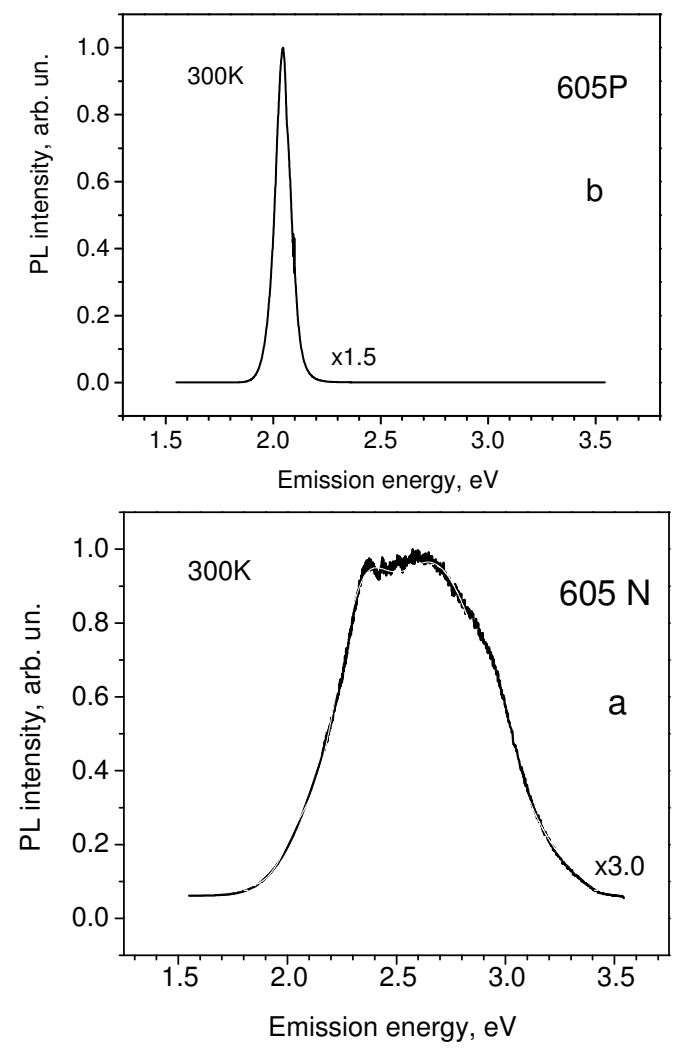

Fig. 14. Nonconjugated (a) and bioconjugated (b) 605 nm CdSe/ZnS QDs (Torchynska et al., 2009b).

Figures 14 and 15 present the PL spectra measured for bioconjugated and nonconjugated QDs. In fresh bioconjugated 605P (Fig. 14.b) and 565P (Fig. 15.b) samples we can see only the PL band 2.04 and $2.20 \mathrm{eV}$, respectively, related to the exciton recombination at ground 
states in the correspondent CdSe cores. The PL intensity of core PL band in 605P QDs increases at bioconjugation that manifests the change of multiplication coefficients from x3.0 in 605N QDs to x1.5 in 605P QDs for normalized PL spectra (Fig. 14). In contrary the PL intensity of core PL band in 565P QDs decreases at bioconjugation that manifests the change of multiplication coefficients from $\times 2.0$ in $565 \mathrm{~N}$ QDs to $\times 3.0$ in 565P QDs for normalized PL spectra (Fig. 15). The FWHM of QD emission bands decreases at the bioconjugation in both types of QDs due to disappearing of the high energy PL bands related to the interface states. This effect was explained in (Torchynska et al., 2009a) on the base of re-charging of interface states at the QD bioconjugation with anti IL-10 antibodies.

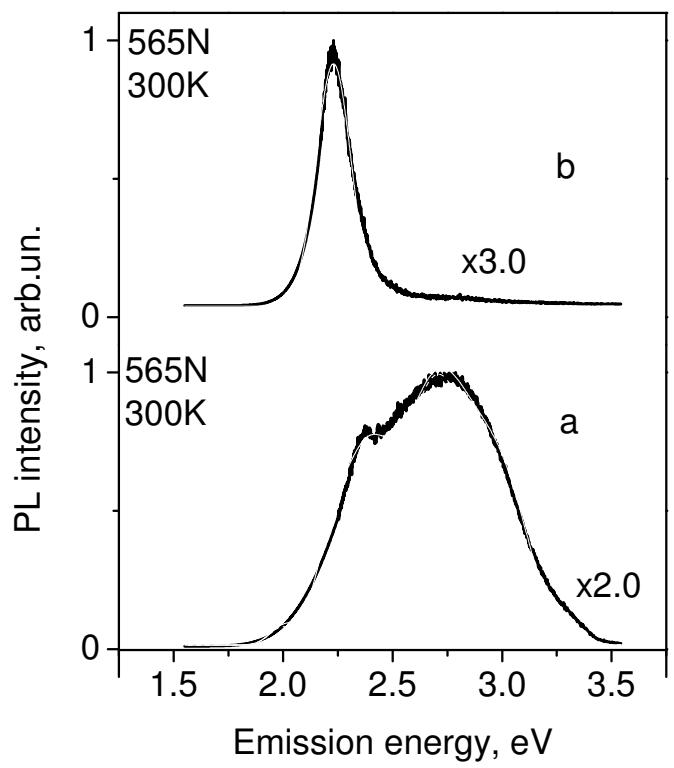

Fig. 15. Nonconjugated (a) and bioconjugated (b) $565 \mathrm{~nm} \mathrm{CdSe/ZnS} \mathrm{QDs} \mathrm{(Vega} \mathrm{Macotela} \mathrm{et}$ al., 2010a).

\section{The model of bioconjugation process for CdSe/ZnS QDs with interface states}

The recombination process in CdSe/ZnS QDs can be considered as the competition of exciton recombination inside the $\mathrm{CdSe}$ core and the hot electron-hole recombination via radiative interface states (Fig. 16) at the CdSe/ZnS or ZnS/polymer interfaces (Torchynska et al., 2009a). The interface states (IS), responsible for the hole trapping in non-conjugated QDs, are negatively charged acceptor-like defects (IS-) (Korsunskaya et al., 1980 a, b; Korsunskaya et al., 1982). Simultaneously, the interface states, responsible for the electron trapping in nonconjugated QDs, are positively charged donor-like defects $\left(\mathrm{IS}^{+}\right)$. The negative charge of acceptor-like interface states is due to their compensation by electrons from donor-like interface states in non-conjugated CdSe/ZnS QDs (Torchynska et al., 2009a). 
Nonconjugated QD

\section{PolymeriTOPO}

\section{Polymer/TOPO}

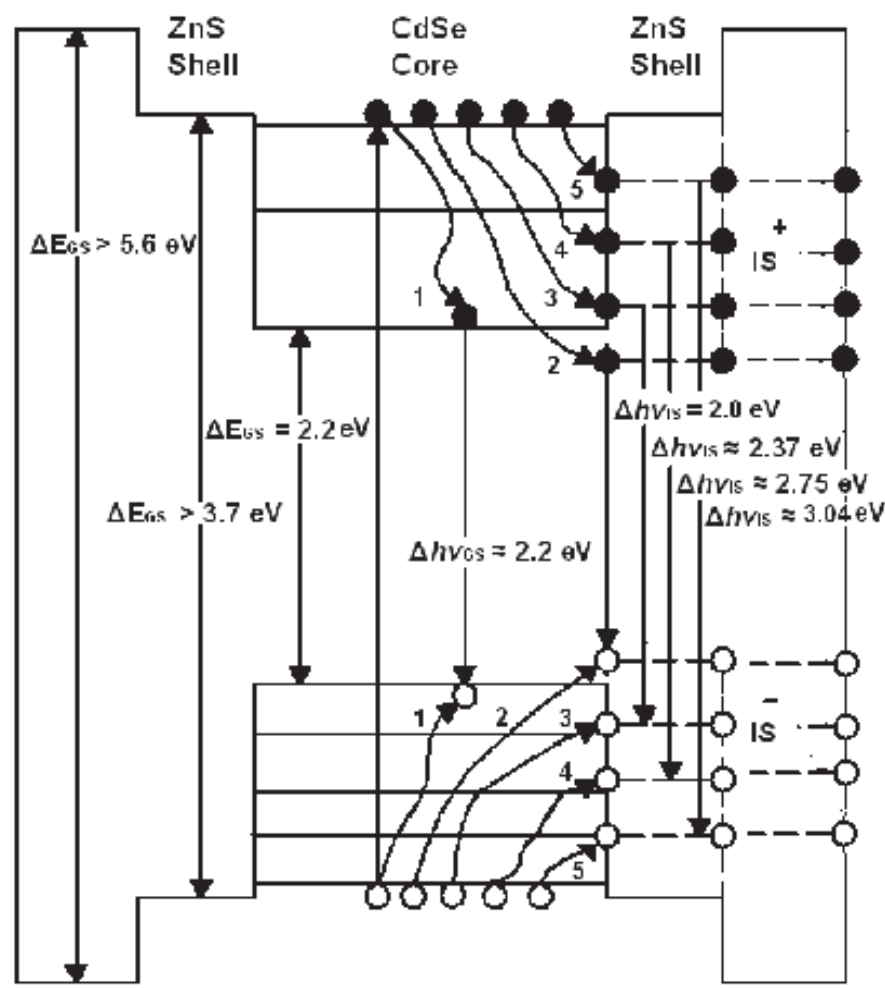

Fig. 16. The energy diagram of CdSe/ZnS core/shell QDs covered by PEG polymer in the nonconjugated state. Symbols IS ${ }^{+}$and IS- present the charge of donor-like and acceptor-like interface states, respectively. Dashed lines show the ways of carrier tunneling from the $\mathrm{CdSe} / \mathrm{ZnS}$ interface toward the ZnS/ polymer interface.

The bioconjugation of proteins with QDs has been achieved through covalent bonds using functional groups (Fig. 13) on the QD surface (Parak et al., 2002) and/or with the help of electrostatic interaction (Ji et al., 2005). Actually the distribution of $\mathrm{H}^{+}$ions along the chain axis in antibody molecules is asymmetric (Antibodies, 2009) that is a reason for the appearance in biomolecules of dipole moments detected at the Raman scattering study (see n.10). It was supposed in (Torchynska et al., 2009a) that in bioconjugated CdSe/ZnS QDs the electrons from donor-like interface states accumulate at the QD surface (or in polymer) where they interact electrostatically with the positively charged antibodies. In this case the electrons from donor-like states do not compensate the acceptor-like interface states of QDs (Fig. 17). Simultaneously, the hot electron-hole recombination flow via neutral acceptor-like interface states decreases dramatically and the PL intensity of exciton emission inside CdSe core increases. Thus, this model assumes that the QD bio-conjugation process is accompanied by the re-charging of acceptor-like interface states in QDs (Fig. 17). 
Actually this effect we have seen in Fig. 14 and Fig. 15 presented in this chapter. The PL intensity of high energy PL bands (2.37, 2.75 and $3.06 \mathrm{eV})$ related to interface states decreases tremendous in bioconjugated QDs that can be explained by recharging of interface states.

\section{The aging of CdSe/ZnS QDs with interface states}

Normalized PL spectra of nonconjugated CdSe/ZnS QDs measured at $300 \mathrm{~K}$ when the QD kits were obtained ( 1 day) and after the aging during 30-110 days demonstrate the broad PL band in the spectral range of 1.80-3.20 eV related to the exciton recombination in the CdSe core and the electron-hole recombination via the interface states (Fig. 18). The concentration of interface states increases due to the PEG polymer modification at the aging in ambient air that leads to the transformation of PL spectra of nonconjugated $605 \mathrm{~nm}$ QDs as it is presented in Fig. 18.

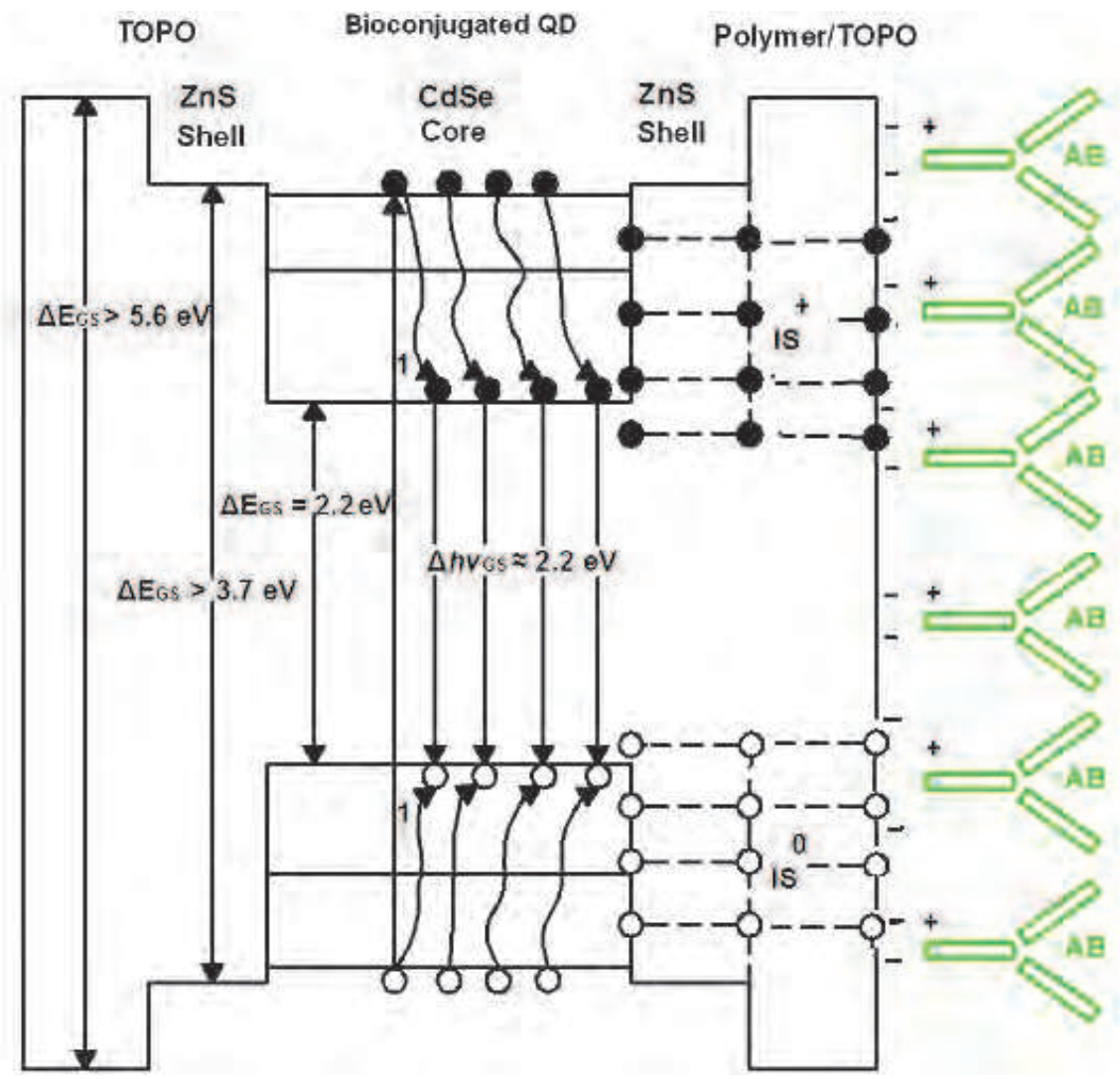

Fig. 17. The energy diagram of CdSe/ZnS QDs covered by polymer in the bioconjugated state. Symbols IS+ and IS ${ }^{+}$present the charge of donor-like and acceptor-like interface states, respectively. Dashed lines show the ways of carrier tunnelling from the CdSe/ZnS interface toward the $\mathrm{ZnS} /$ polymer interface. 


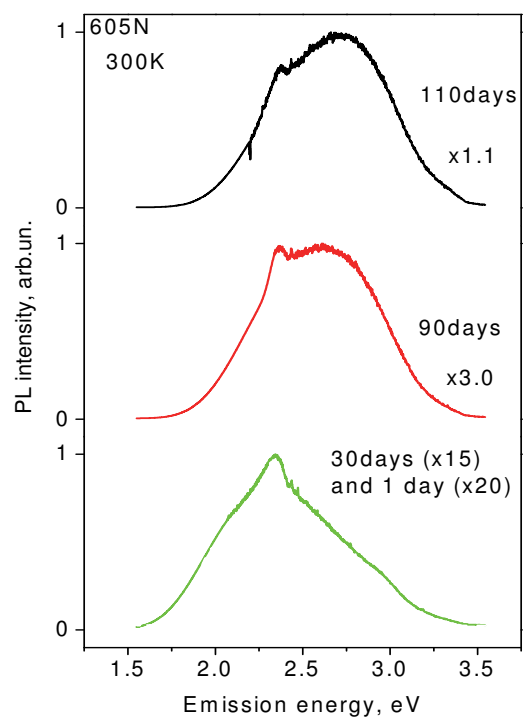

Fig. 18. PL spectra of $605 \mathrm{~N}$ QDs measured in 1 day and after the 30, 90 and 110 days of aging in ambient air. Normalized PL spectra measured at 1 and 30 days coincide, but the multiplication coefficients are different (x20 for 1 day and $x 15$ for 30 days).

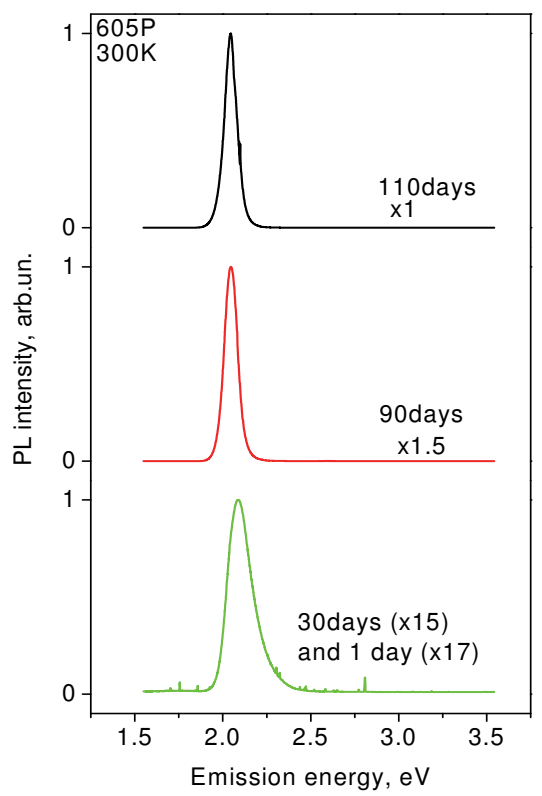

Fig. 19. PL spectra of 605P QDs measured in 1 day and after the 30, 90 and 110 days of aging in ambient air. Normalized PL spectra measured at 1 and 30 days coincide, but the multiplication coefficients are different (x17 for 1 day and x15 for 30 days). 
Fig. 19 presents the PL spectra measured in different aging moments (1, 30, 90 and 110 days) for bioconjugated 605P QDs. In fresh bioconjugated 605P samples (1 day) we can see only the PL band $2.08 \mathrm{eV}$ related to the exciton recombination at ground states in the CdSe core (Fig. 19). The PL intensity of this PL band increases essentially at bioconjugation that manifests the change of multiplication coefficients from $x 20$ in 605N QDs to x17 in 605P QDs for normalized PL spectra measured in the 1 day (Fig. 18 and Fig. 19). At the aging the intensity of CdSe core PL band increases (30-110 days Fig. 19) and its peak position shifts to low energy (red shift) from 2.08 to $2.04 \mathrm{eV}$. The same coefficients (x15) of PL intensity enlargement in the nonconjugated 605N (Fig. 18) and bioconjugated 605P (Fig. 19) QDs with aging during 30-110 days in ambient air testifies that the reason of PL rise on this stage related to transparency increasing of PEG polymer for visible light $(605 \mathrm{~nm})$ at the aging. Let us discuss the "red" shift of CdSe core emission (Fig. 19) for bioconjugated 605P QDs at the aging. It is well known that PL spectra of QDs can be influenced by the environment atmosphere, by thermal annealing or by optical excitation (Nassal et al., 2004). The PL shift can be a result of optically induced adsorption by polar molecules (Oda et al., 2006), or the chemical transformation of species on the QD surface (Cordero et al., 2000; Roberti et al., 1998). This shift can be stimulated by increasing the compressive strain in core/shell QDs at annealing or drying processes as well (Borkovska et al., 2009). We have seen that in nonconjugated QDs the polymer modification during aging in ambient air has induced: i) the enlargement of the concentration of interface states at the $\mathrm{ZnS} /$ polymer interface and ii) the rise of PEG polymer transparency for visible light. The physical aging of polymer is accompanied by the change of polymer density (Rowe et al., 2009; Shelby et al., 1998) and, due to this, by the variation of strain level at the $\mathrm{ZnS} /$ polymer interface. The last factor may be the reason of increasing of the concentration of interface states and the appearance of a red shift of QD emission with aging that has been detected in bioconjugated 605P QDs.

\section{Raman scattering spectra of bioconjugated CdSe/ZnS QDs}

Additionally to the emission study, other optical methods could give inportant information concerning the bioconjugated CdSe/ZnS QDs. Earlier we have shown that the study of Raman scattering of QDs bioconjugated to antibodies can be the powerful technique for the proof of actual bio-conjugation (Torchynska et al., 2007; Torchynska et al., 2008; Vega Macotela et al., 2010b; Diaz-Cano et al., 2010). Moreover in n.8 we supposed for the bioconjugation model of CdSe/ZnS QDs with interface states that antibody molecules are characterized by the dipole moments. This assumption is possible to confirm using the Raman scattering method as well.

Commercially available core-shell CdSe/ZnS QDs with emission at $565 \mathrm{~nm}$ and $605 \mathrm{~nm}$ were bioconjugated to anti PSA and anti IL-10 antibodies, respectively, as it described in n.7. Bioconjugated and nonconjugated QDs samples in a shape of small drops were dried on a surface of crystalline Si substrates (Fig. 14). Raman scattering spectra were measured at 300 $\mathrm{K}$ and the excitation by a He-Ne laser with a wavelength of $632.8 \mathrm{~nm}$ and a beam power of $20 \mathrm{~mW}$ using a setup described in (Torchynska et al., 2007 and 2008).

Fig. 20 and Fig. 21 present the Raman scattering spectra of CdSe/ZnS QDs bioconjugated to anti IL-10 (605P) and to anti PSA (565P) antibodies, respectively, as well as Raman spectra of nonconjugated $(605 \mathrm{~N})$ and $(565 \mathrm{~N})$ samples, for highest intensity Raman peak at $522 \mathrm{~cm}^{-1}$. This peak related to the optical phonon line in a silicon substrate used for studied QD samples. The intensity of these Raman peaks in the nonconjugated $605 \mathrm{~N}$ and $565 \mathrm{~N}$ QD 
samples is tenfold and threefold smaller than in the bio-conjugated 605P and 565P samples, respectively.

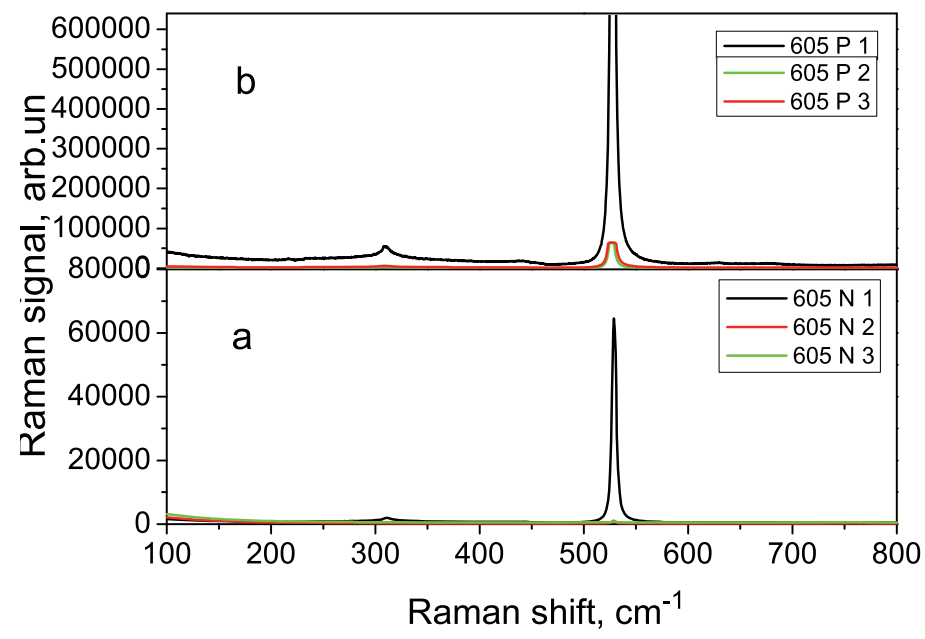

Fig. 20. The main Raman peak of Si substrate in nonconjugated (a) and bioconjugated (b) 605 nm CdSe/ZnS QD samples (Diaz-Cano et al., 2010).

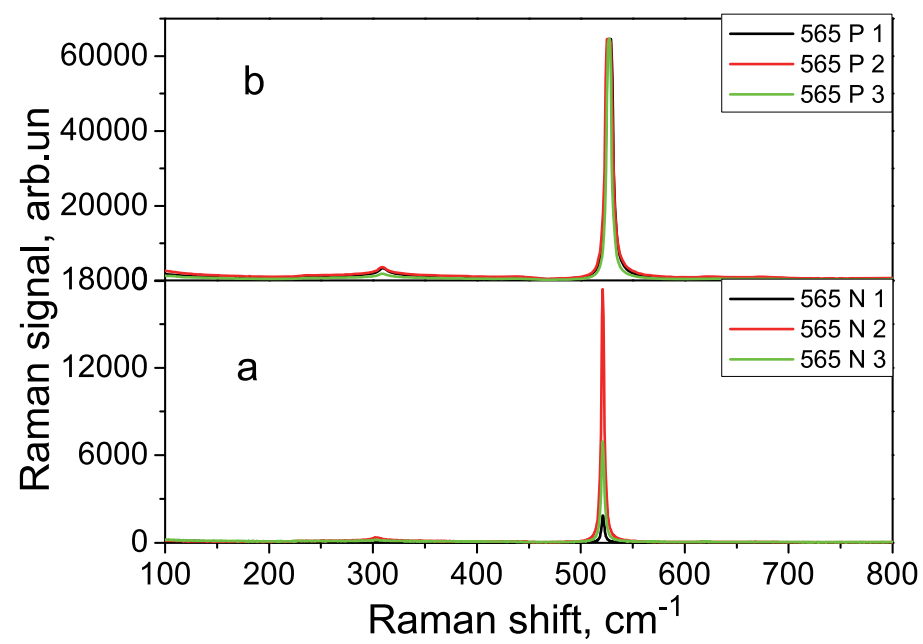

Fig. 21. The main Raman peak of Si substrate in nonconjugated (a) and bioconjugated (b) $565 \mathrm{~nm}$ CdSe/ZnS QD samples (Vega Macotela et al., 2010b).

In some $605 \mathrm{~nm}$ CdSe/ZnS QD samples it is possible to see the enlargement in bioconjugated states the intensity of Raman lines related to the CdSe core and ZnS shell of QDs in comparison with nonconjugated $605 \mathrm{~nm}$ QD samples (Fig. 22). 


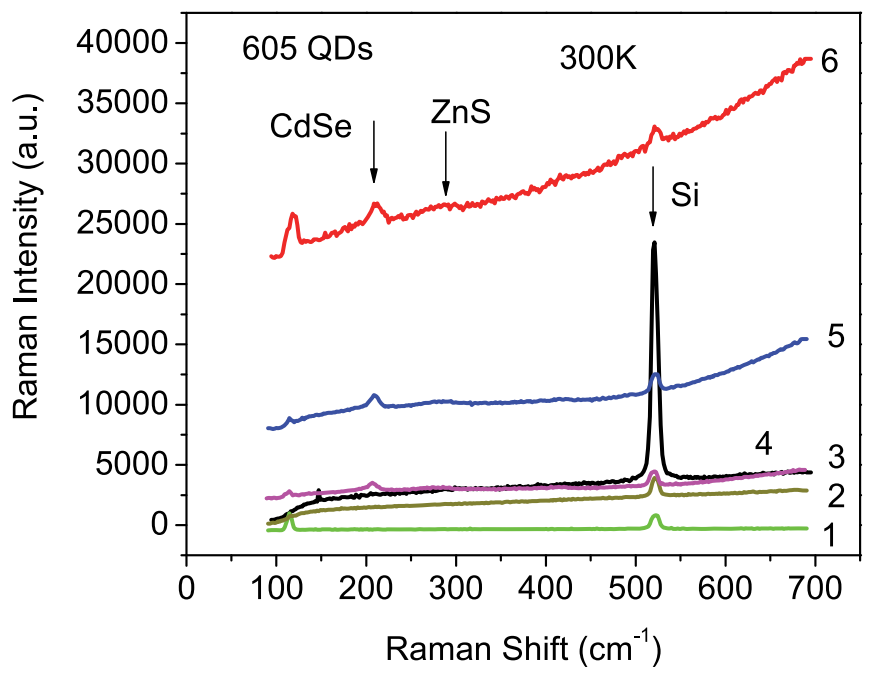

Fig. 22. Raman spectra of a set of nonconjugated $(1,2,3)$ and bioconjugated to anti IL-10 mAb $(4,5,6) 605$ nm CdSe/ZnS QDs (Torchynska et al., 2008).

Fig. 23, Fig. 24, Fig. 25 and Fig. 26 present low intensity Raman peaks related to the Si substrate and obtained in spectral ranges $100-800$ and $800-1050 \mathrm{~cm}^{-1}$ for nonconjugated $(605 \mathrm{~N}$ and $565 \mathrm{~N})$ and bioconjugated (605P and 565P) QD samples. All Raman peaks in the ranges $100-800$ and $800-1050 \mathrm{~cm}^{-1}$ are characterized by the smaller intensities of Raman lines in nonconjugated QD samples $(605 \mathrm{~N}$ and $565 \mathrm{~N})$ than those in bioconjugated QD samples (605P and 565P).

Fig. 27 and Fig. 28 present low intensity Raman peaks related to the PEG polymer on the surface of CdSe/ZnS QDs. These Raman peaks, localized in the spectral range 1050-4000 $\mathrm{cm}^{-1}$, are characterized by different tendencies for the CdSe/ZnS QDs bioconjugated to the anti IL-10 and to the anti PSA antibodies.To understand obtained Raman results the nature of all Raman peaks has to be discussed.

The silicon has the diamond crystal structure and, as a result, demonstrates one first-order Raman active optical phonon of symmetry $\Gamma_{25}$, located at the Brillouin-zone (BZ) center, with the frequency of 519-522 $\mathrm{cm}^{-1}$, Fig. 20 and Fig. 21, Table 2 (Jonson \& Loudon, 1964; Temple \&Hathaway, 1973).

The Raman scattering in the region of $0-500 \mathrm{~cm}^{-1}$ in $\mathrm{Si}$ presents overtones of acoustic phonons. The Raman peaks at 230, 302, 435 and $469 \mathrm{~cm}^{-1}$ were assigned earlier (Temple \&Hathaway, 1973) to the two TA phonon overtones scattered at L, X and near $\Sigma$ critical points, respectively (Table 2). The Table 2 presents the frequencies of optical and acoustical phonons associated with the critical points of the silicon Brillouin zone. Raman peaks at 610 and $670 \mathrm{~cm}^{-1}$ in $\mathrm{Si}$ were assigned to the two-phonon peaks, which, as assumed, are the combinations of acoustic and optic phonons in the $X$ and $\Sigma$ directions (Table 2).

Raman peaks at 236, 308, 441, 620 and $677 \mathrm{~cm}^{-1}$ have been seen clearly in Raman spectra of non-conjugated and bio-conjugated QD samples in Fig. 23 and Fig. 24. Note that Raman peaks related to the CdSe cores $\left(210-212 \mathrm{~cm}^{-1}\right)$ and to the ZnS shell $\left(350 \mathrm{~cm}^{-1}\right)$ have been revealed only in some studied $605 \mathrm{~nm}$ QD samples (Fig. 22). The later may be the result of small quantity of $565 \mathrm{~nm}$ CdSe/ZnS QD materials. 


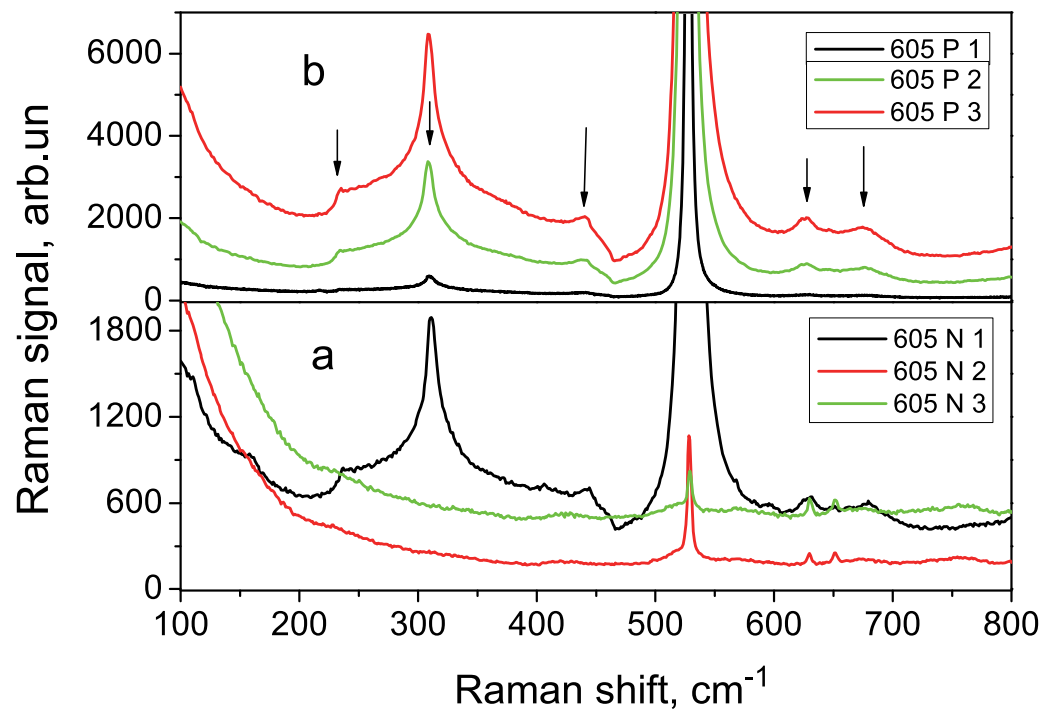

Fig. 23. Raman spectra of nonconjugated (a) and bioconjugated (b) $605 \mathrm{~nm}$ CdSe/ZnS QDs in the range related to the Si substrate (Diaz-Cano et al., 2010).

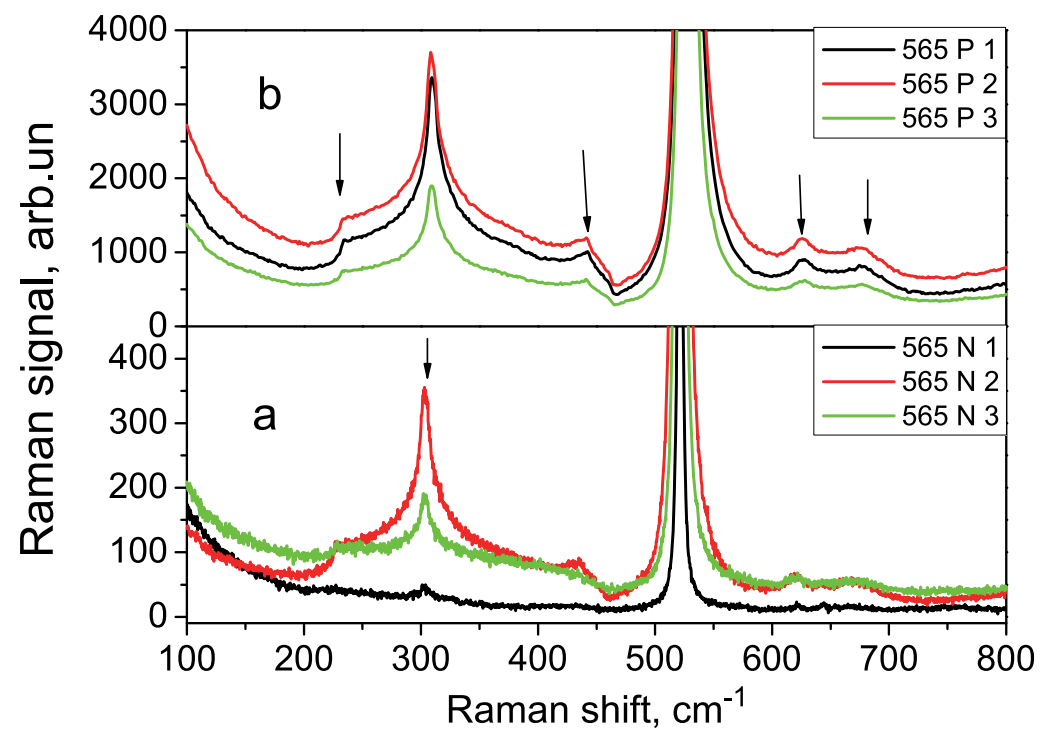

Fig. 24. Raman spectra of nonconjugated (a) and bioconjugated (b) 565 nm CdSe/ZnS QDs in the range related to the Si substrate (Vega Macotela et al., 2010b). 


\begin{tabular}{|c|c|c|}
\hline $\begin{array}{c}\text { Critical points of } \\
\text { Si BZ }\end{array}$ & $\begin{array}{c}\text { Phonon frequencies from } \\
\text { (Jonson \& Loudon, 1964) }\left(\mathrm{cm}^{-1}\right)\end{array}$ & $\begin{array}{c}\text { Phonon frequencies from } \\
\text { (Temple \&Hathaway, 1973) }\left(\mathrm{cm}^{-1}\right)\end{array}$ \\
\hline$\Gamma(0)$ & 522 & 519 \\
X (TO) & 463 & 460 \\
X(TA) & 149 & 151 \\
L(TO) & 491 & 490 \\
L(TA) & 114 & 113 \\
W(TO) & & 470 \\
X(TA+TO) & & 610 \\
$\Sigma($ TA+TO) & & 670 \\
\hline
\end{tabular}

Table 2. Phonon frequencies at the critical BZ points of Si (Temple \&Hathaway, 1973).

The Raman scattering in the $900-1050 \mathrm{~cm}^{-1}$ region in $\mathrm{Si}$ is attributed, as a rule, to overtones of optical phonons. The sharp increase in the Raman spectrum at $920 \mathrm{~cm}^{-1}$ or at $940 \mathrm{~cm}^{-1}$, the shoulder at $975 \mathrm{~cm}^{-1}$ and sharp decrease at $1040 \mathrm{~cm}^{-1}$ were identified earlier (Temple \&Hathaway, 1973) with the two TO phonon overtone scattering from the critical points at X, W, L and $\Gamma$, respectively (Table 2). In studied QD samples, as follows from Fig. 25 and Fig. 26, the Raman peak at $949 \mathrm{~cm}^{-1}$ and the shoulder at $980 \mathrm{~cm}^{-1}$ have been detected as well, which, apparently, related to two TO phonon overtones in Si from the critical points at W and L. Additionally, a set of small intensity Raman peaks at 837, 860, 1011 and $1039 \mathrm{~cm}-1$ have been seen as well (Fig. 25 and Fig. 26). In bio-conjugated QD samples the intensity of Raman peak at $949 \mathrm{~cm}^{-1}$ and a shoulder at $990 \mathrm{~cm}^{-1}$ increase (Fig. 25 and Fig. 26). At the same time, the small intensity Raman peaks 837, 860, 1011 and $1039 \mathrm{~cm}^{-1}$ have disappeared (Fig. 25).

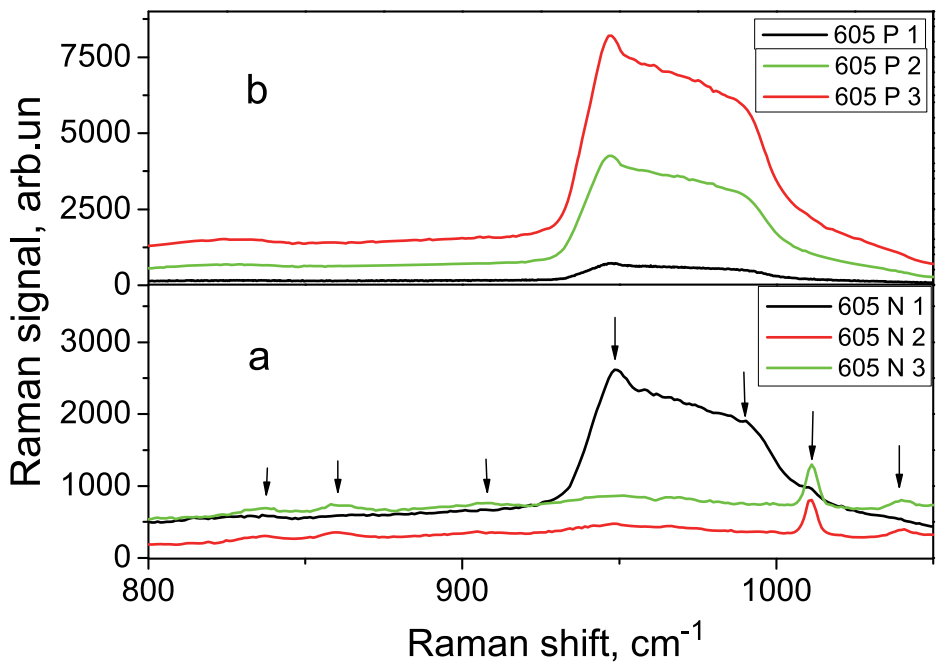

Fig. 25. Raman spectra of nonconjugated (a) and bioconjugated (b) $605 \mathrm{~nm}$ CdSe/ZnS QDs (Diaz-Cano et al., 2010). 


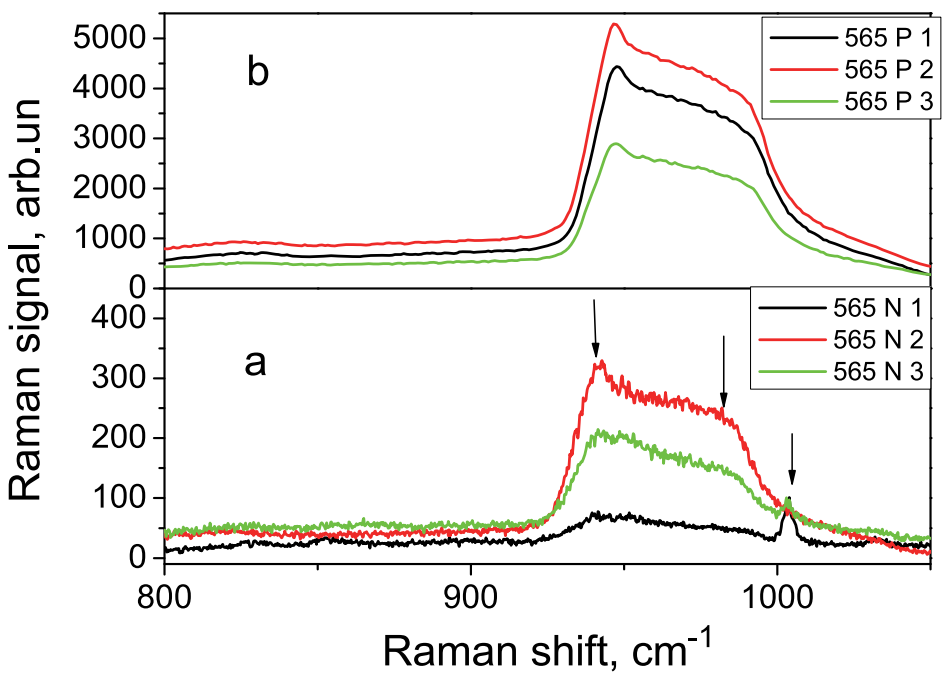

Fig. 26. Raman spectra of nonconjugated (a) and bioconjugated (b) $565 \mathrm{~nm}$ CdSe/ZnS QDs (Vega Macotela et al., 2010b).

In nonconjugated CdSe/ZnS QD samples $(605 \mathrm{~N}$ and $565 \mathrm{~N})$ in the range $1050-4000 \mathrm{~cm}^{-1}$ a set of Raman peaks at 1214, 1273, 1326, 1347, 1413, 1457, 1613, $1661 \mathrm{~cm}^{-1}$ and 2149-2430, 2752, 2880, 2939, 3061 and 3317-3380 $\mathrm{cm}^{-1}$ have been detected as well (Fig. 27 and Fig. 28). These Raman peaks and the small intensity Raman peaks revealed in Fig. 25a (837, 860, 1011 and $\left.1039 \mathrm{~cm}^{-1}\right)$ can be assigned to the vibrations of different groups of atoms in the organic amine $\left(\mathrm{NH}_{2}\right)$-derivatized PEG polymer $\left[\mathrm{OH}-\left(\mathrm{CH}_{2}-\mathrm{CH}_{2}-\mathrm{O}\right)_{n}-\mathrm{H}\right]$ covered the QD surface.

There are: 837, 860 and $1661 \mathrm{~cm}^{-1}$ - PEG skeleton vibrations (Kozielski et al., 2004), 1011 and $1039 \mathrm{~cm}^{-1}$ - stretching vibrations of COH groups, 1214, 1273, 1413 and $1457 \mathrm{~cm}^{-1}$ stretching vibrations of $\mathrm{C}-\mathrm{H}$ bounds and deformation vibrations of $\mathrm{C}-\mathrm{H}$ at 1326 and $1347 \mathrm{~cm}^{-1}$ (Kozielski et al., 2004; Nakamoto 1997), $1613 \mathrm{~cm}^{-1}$ - stretching vibrations of $\mathrm{C}=\mathrm{C}$ bounds and 2149-2430 $\mathrm{cm}^{-1}$ - stretching vibrations of CO or C-N groups (Nakamoto, 1997), symmetric and anti-symmetric stretching vibrations of $\mathrm{CH}, \mathrm{CH}_{2}$ or $\mathrm{CH}_{3}$ groups (2752, 2880, 2939 and $\left.3061 \mathrm{~cm}^{-1}\right)$, as well as the stretching vibrations of $(\mathrm{O}-\mathrm{H})$ and $\left(\mathrm{NH}_{2}\right)$ groups at $3317-3380 \mathrm{~cm}^{-1}$. To confirm that mentioned peaks related to PEG polymers, the QDs without PEG polymer have been studied as well, and, actually, these peaks have been not observed in Raman spectrum.

The intensity enhancement of Raman lines related to the Si acoustic and optical phonons in the bioconjugated QD samples can be attributed to the surface enhanced Raman scattering (SERS) effect (Aroca et al., 2004; Torchynska et al., 2007, 2008, 2009a). The surface electric field enhancement due to the realization of resonance conditions for the plasmon-, phononor exciton-polariton resonances is the known effect in nanocrystals of polar materials (Anderson, 2005). The stimulation of optical field near the interface of illuminated bioconjugated QDs and Si substrate leads to increasing dramatically the intensity of Si Raman lines and in some cases the CdSe core and ZnS shell Raman lines. This fact indicates that the anti IL10 and anti PSA antibodies are characterized by the dipole moments that 
permits them to interact with an electric field of excitation light at the Si surface and to participate in the SERS effect (Torchynska et al., 2007, 2008, 2009a).

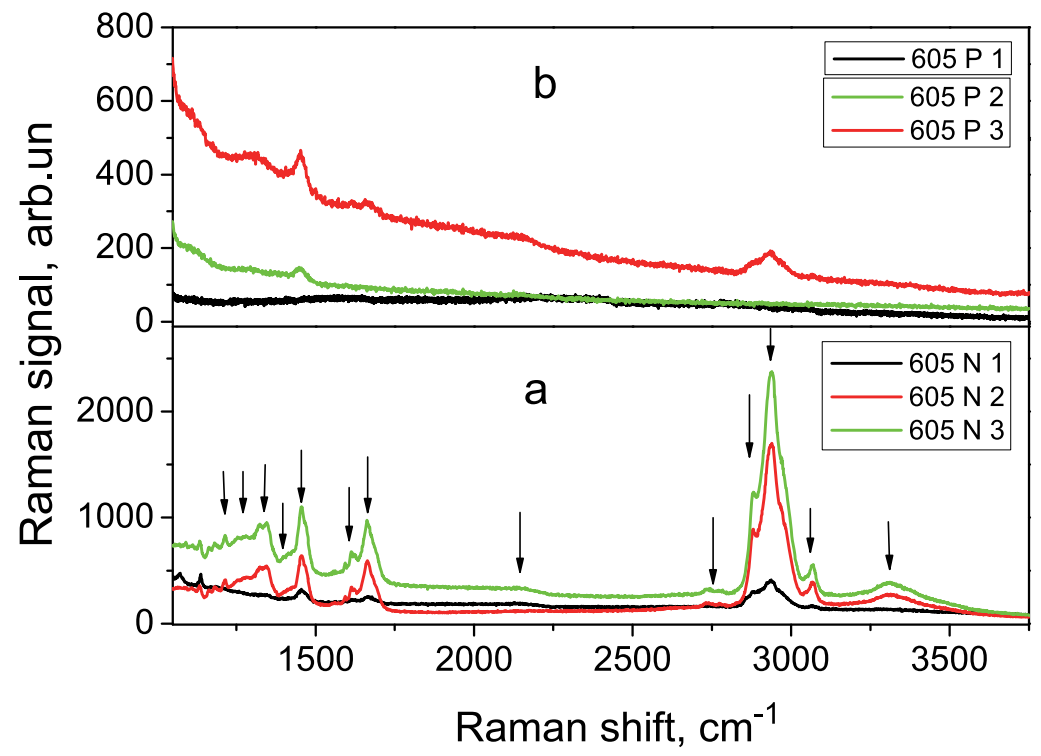

Fig. 27. Raman spectra of nonconjugated (a) and bioconjugated (b) $605 \mathrm{~nm}$ CdSe/ZnS QDs in the range of Raman shift related to the PEG polymer (Diaz Cano et al., 2010).

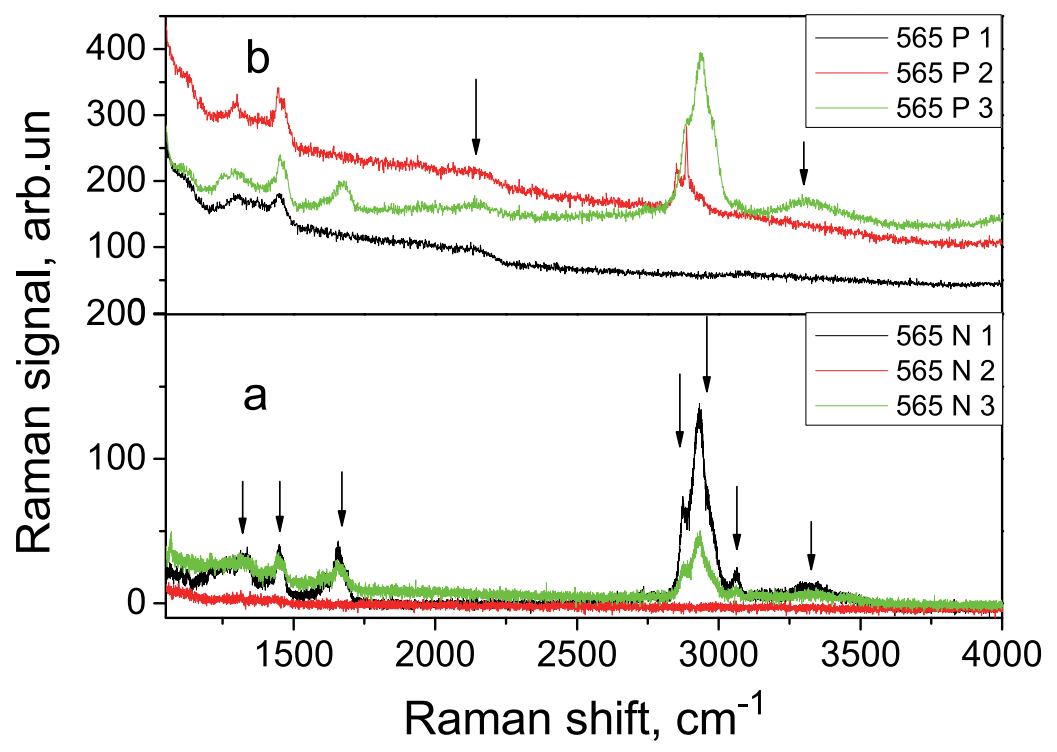

Fig. 28. Raman spectra of nonconjugated (a) and bioconjugated (b) $565 \mathrm{~nm}$ CdSe/ZnS QDs in the range related to the PEG polymer (Vega Macotela et al., 2010b). 
The Raman line intensities of the peaks related to PEG polymer are smaller in nonconjugated $565 \mathrm{~nm}$ QD samples and a little bit increase in bioconjugated $565 \mathrm{~nm}$ QD samples (Fig. 28). In contrary the Raman line intensities of the peaks related to PEG polymer are high in nonconjugated $605 \mathrm{~nm}$ QD samples and decrease in bioconjugated $605 \mathrm{~nm}$ QD samples (Fig. 27). The last fact can indicate on scattering light re-absorption in anti IL-10 antibodies or on other resonance conditions for the vibrations of PEG atomic groups in these samples.

\section{Conclusion}

Thirteen years passed after the first demonstration of cell labelling experiments with colloidal quantum dots. Nowadays colloidal quantum dots are used to address a set of specific biological questions, as well as the numbers of medical applications, that plays an important role in basic life science. Although semiconductor QDs are unlikely to completely replace traditional organic fluorophores, QDs have secured their place as a viable technology in the biological and medical sciences. Their capability for single molecule and multiplexed detection, real-time imaging and biological compatibility, important for drug delivery and photo resonance therapy, makes II-VI material QDs a valuable technology in the scientific toolbox. Additionally II-VI QDs with interface states presented in this chapter permit to spread the experimental possibilities of the biological arsenal.

The work was partially supported by CONACYT Mexico (projects 000000000131184 and 00000000130387), as well as by the SIP-IPN, Mexico.

\section{References}

Aldana, J., Wang, Y.A., Peng, X.G. (2001). Photochemical Instability oof CdSe Nanocrystals Coated by Hydrophilic Thiols. J. Am. Chem. Soc., Vol. 123, 8844-8850.

Alivisatos, A.P., Harris, D., Carroll, J., Steigerwald, M.L., Brus, L. (1989). Electrochemical Synthesis and Laser Induced Time Resolved Photoluminescence of CdSe/ZnS Quantum Dots. Chem. Phys., Vol. 90, pp. 3463-3470.

Alivisatos, A.P. (1996). Semiconductor Clusters, Nanocrystals and Quantum Dots. Science, Vol. 271, pp. 933-937.

Anderson, M.S. (2005). Surface Enhanced Infrared Absorption by Coulping Phonon and Plasma Resonance. Appl. Phys. Lett., Vol. 87, 144102.

Antibodies (2009). http:/ / en.wikipedia.org/wiki/

Aroca, R.F., Ross, D.J., Domingo, C. (2004). Surface-Enhanced Infrared Spectroscopy. Appl. Spectrosc., Vol. 58, pp. 324A-338A.

Bailey, R.E., Smith, A.M., Nie, Sh. (2004). Quantum Dots in Biology and Medicine. Physica E, Vol. 25, pp. 1-12.

Baranov, A.V., Rakovich, Yu.P., Donegan, J.F., Perova, T.S., Moore, R.A., Talapin D.V., Rogach, A.L., Masumoto, Y., Nabiev, I. (2003). Effect of ZnS Shell Thickness on the Phonon Spectra in CdSe Quantum Dots. Phys.Rev. B, Vol. 68, 165306.

Biju, V., Makita, Y., Nagase, T., Yamaoka ,Y., Yokoyama, H., Baba Y., Ishikawa, H. (2005a). Subsecond Luminescence Intensity Fluctuations of Single CdSe Quantum Dot. J Phys Chem B. Vol. 109, pp. 14350-14355. 
Biju, V., Makita, Y., Sonoda, A., Yokoyama, H,. Baba, Y., Ishikawa, M. (2005b). Temperaturesensitive photoluminescence of CdSe quantum dot clusters. J Phys Chem B, Vol. 109, pp. 13899-13905.

Borkovska, L.V., Korsunska, N.E., Kryshtab, T.G., Germash, L.P., Pecherska, E.Yu.., Ostapenko, S., and Chornokur, G. (2009). Semiconductors, 43, 775 (2009).

Brigger, I., Dubernet, C., Couvreur, P. (2002). Nanoparticles in Cancer Therapy and Diagnosis. Adv. Drug Deliv Rev., Vol. 54, pp.631-651.

Bruchez M, Moronne M, Gin P, Weiss S, Alivisatos AP. (1998). Science, Vol. 281, pp. 20132016.

Calvo P, RemunanLopez C, VilaJato JL, Alonso MJ. J Appl Polym Sci 1997;63:125-32.

Choi, S.-H., Song, H., Park, I.K., Yum, J.-H., Kim, S.-S., Lee, S. and Sung, Y.-E. (2006). Synthesis of Size-Controlled CdSe Quantum Dots and Characterization of CdSeconjugated Polymer Blends for Hybrid Solar Cells.

Chin, I.L., Abraham, K.J., Chao Kang Chang, Yu Der Lee. (2004). Synthesis and Photoluminescence Study of Molecularly I mprinted Polymers Appended onto CdSe/ZnS Core-Shell. Biosensors and Bioelectronics, Vol. 20, pp. 127-131.

Chan, W.C.W., Nie, S. (1998). Science, Vol. 281, pp.2016-2018.

Clapp, A.R., Medintz, I.L., Mauro, J.M., Fisher, Br.R., Bawendi, M.G. and Mattoussi, H. (2004). Fluorescence Resonance Energy Transfer between Quantum Dot Donors and Dye-Labeled Protein Acceptors. J. AM. Chem. Soc. Vol. 126, pp. 301-310.

Cordero, S.R., Carson, P.J., Estabrook, R.A., Strouse, G.F., \& Buratto, S.K. (2000). J. Phys. Chem. B 104, 12137 (2000).

Crouch, D., Norager, S., O’Brien, P., Park, J.H. and Pickett, N. (2003). New synthetic routes for quantum dots. Phil. Trans. R. Soc. A, Vol. 361, pp. 297-310.

Dabbousi, B.O., Rodriguez-Viejo, J., Mikulec, F.V., Heine, J.R., Mattoussi, H., Ober, R., Jensen, K.F., Bawendi, M.G. (1997). (CdSe)ZnS Core-Shell Quantum Dots: Synthesis and Characterization of a Size Series of Highly Luminescent Nanocrystallites. J. Phys. Chem. B, Vol.101 pp. 9463-9475.

Danek, M., Jensen, K.F., Murray, C.B. and Bawendi, M.G. (1994). Preparation of II-VI quantum dot composites by electrospray organometallic chemical vapor deposition. J. Crys. Growth, Vol. 145, pp. 714-720.

Darbandi, M., Thomann, R., Nann, T. (2005). Single Quantum Dots in Silica Spheres by Microemulsion Synthesis. Chem. Mater., Vol. 17 pp. 5720-5725.

Diaz Cano, A., Jiménez Sandoval S., Vorobiev, Y., Rodriguez Melgarejo, F. and Torchynska, T.V. (2010). Peculiarities of Raman scattering in bioconjugated CdSe/ZnS quantum dots, Nanotechnology, Vol. 21, 134016.

Dinger, A., Hetterich, M., Goppert, M., Grun, M., Weise, B., Liang, J., Wagner, V., Geurts, J. (1999). J. Cryst. Growth Vol. 200, pp. 391-397.

Dubertret, B., Skourides, P., Norris, D.J., Noireaux, V., Brivanlou, A.H. (2002). In Vivo Imaging of Quantum Dots Encapsulated ij Phospholipid Micelles. Science, Vol. 298, pp. 1759-1762.

Dubertret, J.K., Mattoussi, H., Mauro, J.M., Simon, S.M. (2003). Long-term multiple color imaging of live cells using quantum dot bioconjugates. Nat Biotechnol., Vol. 21, pp. 47-51. 
Dybiec, M., Chomokur, G., Ostapenko, S., Wolcott, A., Zhang, J.Z., Zajac, A., Phelan, C., Sellers, T., Gerion, G. (2007). Photoluminescence Spectroscopy of Bioconjugated CdSe/ZnS Quantum Dots. Appl. Phys. Lett. Vol. 90, No. 26, 263112.

Dzhagan, V.M., Valakh, M.Ya., A E Raevskaya, A.E., Stroyuk, A.L., S Ya Kuchmiy, S.Ya. and D R T Zahn, D.R.T. (2007). Nanotechnology Vol. 18, 285701.

Dzhagan, V.M., Valakh, M.Ya., Raevskaya, A.E., .L. Stroyuk, A.L., Kuchmiy, S.Ya., D.R.T. Zahn, D.R.T. (2008). Appl. Surf. Sci., Vol. 255, pp.725-727.

Ebenstein, Y., Mokari, T., Banin, U. (2004). Quantum-Dot-Functionalized Scanning Probes for Fluorescence-Energy-Transfer-Based Microscopy. J. Phys. Chem. B., Vol. 108, pp. 93-99.

Eisler H.J.; Sundar V.C.; Bawendi M.G.; Walsh M.; Smith H.I.; Klimov V.I. (2002). Colorselective Semiconductor Nanocrystal Laser. Appl. Phys. Lett. Vol. 80, No. 24, pp. 4614-4616.

Efros, Al.L., Rosen, M., Kuno, M., Nirmal, M., Norris, D.J., and M. Bawendi, M. (1996). Band-edge Exciton in Quantum Dots of Semiconductors With a Degenerate Valence Band. Phys. Rev. B, Vol. 54, No. 7, 4843.

Éfros, Al.L., Éfros, A.L. (1982). Interband absorption of light in a semiconductor sphere. Sov. Phys. Semicond., Vol.16(7), pp. 772-775.

Esparza-Ponce, H., Hernández-Borja, J., Reyes-Rojas, A., Cervantes-Sánchez, M., Vorobiev, Y.V., Ramirez-Bon, R., Pérez-Robles, J.F., González-Hernández, J. (2009). Growth technology, X-ray and optical properties of CdSe thin films. Materials Chemistry and Physics, Vol. 113, pp. 824-828

Gao, X.H., Cui, Y.Y., Levenson,R.M., Chung, L.W.K., Nie S.M. (2004). In Vivo Cancer Targeting with Semiconductor Quantum Dots. Nat Biotechnol, Vol. 22, pp. 969-976.

Gaponenko, S.V. (1998). Optical Properties of Semiconductor Nanocrystals, Cambridge University Press, ISBN 0-521-58241-5, Cambridge.

Gerion, D., Pinaud, F., Williams, Sh.C., Parak, W.J., Zanchet, D., Weiss, Sh. and Alivisatos, A.P. (2001). Synthesis and Properties of Biocompatible Water-Soluble Silica-Coated CdSe/ZnS Semiconductor Quantum Dots. J. Phys. Chem. B, Vol. 105, pp. 8861-8871 .

Gerion, D., Parak, W.J., Williams, S.C., Zanchet, D., Micheel, C.M., Alivisatos, A.P. (2002). Sorting Fluorescent Nanocrystals with DNA. J Am Chem Soc., Vol. 124, pp. 70707074 .

Grodzinski, P., Silver, M., Molnar, L.K. (2006). Nanotechnology for Cancer Diagnostics: Promises and Challenges. Expert Rev. Mol. Diagn., Vol. 6, No. 6, pp. 307-318.

Guo, W., Jack Li, J., Wang, J.A., Peng, X. (2003). Conjugation Chemistry and Bioapplications of Semiconductor Box Nanocrystals Prepared via Dendrimer Bridging. Chem. Mater., Vol. 15, pp. 3125-3133.

Gao, X.H., Gui, Y.Y., Levenson, R.M., Chung, L.W.K., Nie, S.M. (2004). In Vivo Cancer Targeting and Imaging with Semiconductor Quantum Dots. Nature Biotechnol., Vol. 22(8), pp. 969-976.

Greenham, N.C., Peng, X., Alivisatos, A.P. (1997). Charge Separation and transport in conjugated polymer/cadmium selenide nanocrystal composites studied by photoluminescence quenching and photoconductivity. Synthetic Metals 1997, Vol. 84, pp. 545-546.

Ferrari, M. (2005). Cancer Nanotechnology: Opportunities and Challenges. Nature Reviews, Vol. 5, pp. 161-171. 
Fogg, D.E., Radzilowski, L.H., Dabbousi, B.O., Schrock, R.R.;, Thomas E.L., Bawendi, M.G. (1997). Fabrication of Quantum Dots/Polymer Composites. Macromolecules 1997, Vol. 30, pp. 8433-8439.

Hai, L.B., Nghia, N.X., Nga, P.T., Manh, D.H., Hanh, V.T.H. and Trang, N.T.T. (2009). Influence of Cd:Se Precursor Ratio on Optical Properties of Colloidal CdSe Tetrapods Prepared in Octadecene. J. Phys: Conf. Ser., Vol. 187, 012027.

Han, M.Y., Gao, X.H., Su, J.Z., Nie, S. (2001). Quantum-Dot-Tagged Microbeads for Multiplexed Optical Coding of Biomolecules. Nat. Biotechnol, Vol. 19, pp. 631-635.

Hanaki, K., Momo, A., Oku, T., Komoto, A., Maenosono, S., Yamaguchi, Y., Yamamoto, K. (2003). Semiconductor quantum dot/albumin complex is a long-life and highly photostable endosome marker. Biochem Biophys Res Commun, Vol. 302, pp. 496-501.

Haus, J.W., Zhou, H.S., Honma, Komiyama, J.H. (1993). Phys. Rev. B, Vol. 47, pp. 1359-1365, 1993.

Heine, J.R., Rodriguez-Viejo, J., Bawendi, M.G. and Jensen, K.F. (1998). Synthesis of CdSe quantum dot ZnS matrix thin films via electrospray organometallic chemical vapor deposition. J. Cryst. Growth, Vol. 195, pp. 564-568.

Hines, M.A., Guyot-Sionnest, P. (1996). Synthesis and Characterization of Strongly Luminescing ZnS-Capped CdSe Nanocrystals J. Phys. Chem., Vol. 100, pp. 468-471. Hwang, Y.N., Park, S.H., Kim, D. (1999). Size-dependent Surface Phonon Mode of CdSe Quantum Dots. Phys. Rev.B, Vol. 59, 7285.

Hwang, Y.N., Park, S.H., Kim, D. (1999). Size-dependent Surface Phonon Mode of CdSe Quantum Dots. Phys. Rev.B, Vol. 59, 7285.

Hong-Mei Gong \& Zhang-Kai Zhou \& Hao Song \& Zhong-Hua Hao \& Jun-Bo Han \& YueYing Zhai \& Si Xiao \& Qu-Quan Wang, J Fluoresc (2007) 17:715-720.

Hoener, C. F.; Allan, K. A.; Bard, A. J.; Campion, A.; Fox, M. A. Mallouk, T. E.; Webber, S. E.; White, J. M. J. Phys. Chem. 1992, 96, 3812.

Hoshino, A., Manabe, N., Fujioka, K., Suzuki, K., Yasuhara, M. and Yamamoto, K. (2007). Use of Fluorescent Quantum Dots Bioconjugates for Cellular Imaging of Immune Cells, Cell Organelle Labeling, and Nanomedicine: Surface Modification Regulates Biological Function, Including Cytotoxicity. J. Artif. Organs, Vol. 10, No. 3, pp. 149157.

Huang DBPPV-CdSe-ZnS Quantum-Dot Light-Emitting Diodes. IEEE Photonics Technol. Lett., Vol, C.Y., Su, Y.-K., Wen, T.-C., Guo, T.-F., and Tu, M.-L. (2008). SingleLayered Hybrid. 20, No. 4, pp. 282-284.

Huynh, W.U., Peng, X., Alivisatos, A.P. (1999). Preparation and Characterization of CdSe Nanoparticles Prepared by Using Ultrasonic Irradiation. Adv. Mater., Vol. 11, pp. 923-938.

Huynh, W.U., Dittmer, J.J., Alivisatos, A.P. (2002). Hybrid Polymer-Nanorod Solar Cell. Science, Vol. 295, No. 5564, pp. 2425-2427.

Invitrogen - a Provider of Essential Life Science Technologies (2010). http://www.invitrogen.com

Jaiswal J.K.; Mattoussi H.; Mauro J.M.; Simon S.M. Nature Biotechnol. 2003,21, 47.

Jamieson, T., Bakhshi, R., Petrova, D., Pocock, R., Imani, M., Seifalian, A.M. (2007). Biological Applications of Quantum Dots. Biomaterials Vol. 28, pp. 4717-4728. 
Ji, X., Zheng, J., Xu, J., Rastogi, V.K., Cheng, T.Ch., DeFrank, J.J. and Leblanc, R.M. (2005). (CdSe)ZnS Quantum Dots and Organophosphorus Hydrolase Bioconjugate as Biosensor for Detection of Paraoxon. J. Phys. Chem. B, Vol. 109, pp. 3793-3799.

Johnson, F.A., and Loudon, R. (1964). Proc. Roy. Soc. A, Vol. 281, 274-277.

Kim, S., Fisher, B., Eisler, H.-J., Bawendi, M. (2003). Type-II quantum dots: $\mathrm{Te} / \mathrm{CdSe}$ (core/shell) and CdSe/ZnTe(core/shell) heterostructures. J Am Chem Soc Vol. 125, pp. 11466-11567.

Kim, S., Bawendi, M.G. (2003). Oligomeric Ligands for Luminescent and Stable Nanocrystal Quantum Dots. J Am Chem Soc, Vol. 125, pp. 14652-14653.

Kirchner, C., Leidl, T., Kudera, S. (2005). Cytoxicity of Colloidal CdSe and CdSe/ZnS Nanoparticles. Nano Lett., Vol. 5(2), pp. 331-338.

Klude, M., Passow, T., Heinke, H. and Hommel, D. (2002). Electro-Optical Characterization of CdSe Quantum Dot Laser Diode. Phys. Status Solidi (b), Vol.229, No.2, pp. 10291052.

Kongkanand, A., Tvrdy, K., Takechi, K., Kuno, M, and Kamat, P.V. (2008). Quantum Dots Solar Cells. J. Am. Chem. Soc. Vol. 130, 4007-4015. (2008).

Kortan, A.R.; Hull, R., Opila, R.L., Bawendi, M.G., Steigerwald, M.L., Carroll, P.J., Brus, L.E. (1990). Nucleation and Growth of Cadmium Selenide on Zinc Sulfide Quantum Crystallite Seeds, and Vice Versa, in Inverse Micelle Media. J. Am. Chem. Soc. Vol. 112 , pp. 1327-1332.

Kuno, M., Fromm, D.P., Hamann, H.F., Gallagher, A., Nesbitt, D.J. (2001). "On" /"off" Fluorescence Intermittency of Single Semiconductor Quantum Dots. J. Chem. Phys. Vol. 115, pp. 1028-1031.

Korsunskaya, N.E., Markevich, I.V., Torchinskaya, T.V. and Sheinkman, M.K. (1980a). Photosensitivity Degradation Mechanism in CdS:Cu Single Crystals , phys. stat. sol (a), Vol. 60, pp. 565-572.

Korsunskaya, N.E., Markevich, I.V., Torchinskaya, T.V. and Sheinkman, M.K. (1980b). Electrodiffusion of shallow donors in CdS crystals, J.Phys.C. Solid St.Phys., Vol. 13, pp. $2975-2978$.

Korsunskaya, N.E., Markevich, I.V., Torchinskaya, T.V. and Sheinkman, M.K. (1982). Recharge-enhanced transformations of donor-acceptor pairs and clusters in CdS J. Phys. Chem. Solid. Vol. 43, pp. 475-479.

Kozielski, M., Muhle, M., Z. Blaszczak, Z. (2004). J. Molecul. Liquid. Vol. 111, pp. 1-5.

Larson, D.R., Zipfel, W.R., Williams, R.M., Clark, S.W., Bruchez, M.P., Wise, F.W., Webb, W.W. (2003). Water-Soluble Quantum Dots for Multiphonon Fluorescence Imaging in Vivo. Science, Vol. 300, pp. 1434-1436.

Lee, LY., Ong, S.L., Hu, J.Y., Ng, W.J., Feng, Y.Y., X.L. Tan, X.L. (2004). Use of Semiconductor Quantum Dots for Photostable Immunofluorescence Labeling of Cryptosporidium parvum. Appl Environ Microbiol, Vol. 70, pp. 5732-5736.

Liu,Y., Qiu, H.Y., Xu, Y., Wu, D., Li, M.J., J.X. Jiang, J.X. and G.Q. Lai, G.Q. (2007). Synthesis and Optical Properties of CdSe nanocrystals and CdSe/ZnS Quantum Dots. J. Nanopart. Res., Vol. 9, pp. 745-747.

Liang, J.G., Huang, S., Zeng, D., He, Z., Ji, X. and Yang, H. (2006). Highly Luminescent CdTe Quantum Dots Prepared in Aqueous Phase as an Altenative Fluorescent Probe for Cell Imaging. Talanta, Vol. 69, pp. 126-129. 
Liboff, R.L., Greenberg, J. (2001). The Hexagon Quantum Billiard. J. Stat. Phys. Vol. 105, pp. 389-402

Liboff, R.L. (1994). The Polygon Quantum Billiard Problem. J. Math. Phys. Vol. 35, No.2, pp. 596-607

Lopez-Luke, T., Wolcott, A., Xu, L.P., Chen, S.W., Wcn, Z.H., Li, J.H., De La Rosa, E. and Zhang, J.Z. (2008). Conjugating Luminescent CdTe Quantum Dots with Biomolecules. J. Phys. Chem. C, Vol. 112, pp. 1282-1287.

Lou, X., Weng, W.J., Du, P.Y., Shen, G. and Han, G.R. (2004). Synthesis and Optical Properties of CdSe Nanocrystals and CdSe/ZnS Quantum dots. Rare Met. Mater. Eng., Vol. 33, pp. 291-299.

Madelung, O. (Ed.). (1992). Semiconductors, Data in Science and Technology. Springer-Verlag, Berlin.

Malik, M.A., O'Brien, P. and Revaprasadu, N. (2005). Precursor Routes to Semiconductor Quantum Dots. Phos. Sulfur Silicon Relat. Elem., Vol. 180, pp. 689-712.

Mattoussi, H., Radzilowski, L.H., Dabbousi, B.O., Fogg, D.E., Schrock, R.R., Thomas, E.L., Rubner, M.F., Bawendi, M.G. (1999). Composite Thin Films of CdSe Nanocrystals and a Surface Passivating/Electron Transporting Block Copolymer. J. Appl. Phys. 1999, Vol. 86, 4390-4399.

Mattoussi, H., Mauro, J.M., Goldman, E.R., Anderson, G.P., Sundar, V.C., Mikulec, F.V. (2000). Self-Assembly of CdSe-ZnS Quantum Dots Bioconjugates Using an Engineered Recombinant Protein. J Am. Chem Soc., Vol.122, pp.12142-12150.

Medintz IL, Uyeda HT, Goldman ER, Mattoussi H. Nat Mater 2005;4:435-46.

Meulenberg, R.W., Jennings, T., Stroue, G.F. (2004). Compressive and Tensile Stress in Colloidal CdSe Semiconductor Quantum Dots. Phys. Rev. B, Vol. 70, No. 23, 235311.

Miyazaki S, Yamaguchi H, Takada M, Hou WM, Takeichi Y, Yasubuchi H. Acta Pharm Nordica 1990;2:401-6.

Murcia, M.J.; Shaw, D.L.; Long, E.C.; Naumann, C.A. (2008). Fluorescence Correlation Spectroscopy of CdSe/ZnS Quantum Dots Optical Bioimaging Probes with UltraThin Biocompatible Coating. Opt. Commun., Vol. 281, No. 7, pp. 1771-1780.

Murray, C.B., Norris, D.J., Bawendi, M.G. (1993). Synthesis and Characterization of Nearly Monodisperse $\mathrm{CdE}(\mathrm{E}=$ Sulfur, Selenium, Tellurium) Semiconductor Nanocrystallites. J Am.Chem.Soc., Vol. 115, pp. 8706-8715.

Murray, C.B., Kagan, C.R., Bawendi, M.G. (2000). Synthesis and Characterization of Monodisperse Nanocrystals and Close-Packed Nanocrystal Assemblies. Annu. Rev. Mater. Sci., Vol. 30, pp. 545-610.

Murray, C.B., Sun, S., Gaschler, W., Doyle, H., Betley, T.A., C.R. Kagan, C.R. (2001). Colloidal synthesis of nanocrystals and nanocrystal superlattices. IBM J. Res. Dev., Vol. 45, pp. 47-56.

Nakamoto, K. (1997). Infrared and Raman Spectra of Inorganic and Coordination Compounds, Part A, John Wiley \&Sons, Inc., N.Y.

Nann, T. and Riegler, J. (2002). Monodisperse CdSe Nanorods at Low Temperatures. Chem. Eur. J., Vol. 8, No. 20, pp. 4791-4795.

Nazzal, A.Y., X. Y. Wang, X.Y., Qu, L.H., Yu, W., Wang, Y.Z., Peng, X.G., and Xiao, M. (2004). J. Phys. Chem. B Vol. 108, pp. 55075511.

Nordell, K.J., Boatman, E.M., Lisensky, G.C. (2005). A Safer, Easier, Faster Synthesis for CdSe Quantum Dot Nanocrystals. J. Chem.Educ., Vol. 82, pp. 1697-1699. 
Norris, D.J., Bawendi, M.G. Measurement and Assignment of the Size-Dependent Optical Spectrum in CdSe Quantum Dots. (1996). Phys. Rev. B, 53, 16338.

Norris, D.J., Efros, Al.L., Rosen, M. and Bawendi, M.G. (1996). Size Dependence of Exciton Fine Structure in CdSe Quantum Dots. Phys.Rev. B, Vol.53, No. 24, 16347.

Oda, M., Tsukamoto, J., Hasegawa, A., Iwami, N., K. Nishiura, Hagiwara, I., Amdo, N., Horiuchi, H. and Tani, T. (2006). J. Luminecs., Vol. 119-120, pp. 570-573.

Parak, W.J., Gerion, D., Zanchet, D., Woerz, A.S., Pellegrino, T., Micheel, Ch., Williams, Sh.S., Seitz, M., Bruehl, R.E., Bryant, Z., Bustamante, C., Bertozzi, C.R. and Alivisatos, A.P. (2002). Conjugation of DNA to Silanized Colloidal Semiconductor Nanocrystalline Quantum Dots. Chem. Mater., Vol. 14, pp. 2113-2119.

Park, J., An, K., Hwang, Y., Park, J.E.G., Noh, H., Kim, J., Park, J., Hwang, N.M. and Hyeon, T. (2004). Ultra-large Scale Synthesis of Monodisperse nanocrystals. Nat. Mater., Vol. 3, pp. 891-895.

Park, J., Lee, K.H., Galloway, J.F. and Searson, P.C. (2008). Synthesis of Cadmium Selenide Quantum Dots from a Non-Coordinating Solvent: Growth Kinetics and Particle Size Distribution. J. Phys. Chem. C, Vol. 112, pp. 17849-17854.

Parungo, C.P., Ohnishi, S., Kim, S.W., Kim, S., Laurence, R.G., Soltesz, E.G. (2005). Intraoperative Identification of Esophageal Sentinel Limph Nodes Using NearInfrared Fluorescence Imaging. J Thorac. Cardiovasc Surg., Vol. 129, pp. 844-850.

Pathak, S., Choi, S.K., Arnheim, N., M.E. Thompson, M.E. (2001). Hydroxylated Quantum Dots as Luminescent Probes for in Situ Hybridization. J. Am. Chem. Soc . Vol. 123, pp. 4103-4104.

Pellegrino T, Manna L, Kudera S, Liedl T, Koktysh D, Rogach AL, Nano Lett 2004;4:703-7.

Peng, X., Schlamp M.C., Kadavanich A.V., Alivisatos A.P. (1997). Epitaxial Growth of Highly Luminescent CdSe/CdS Core/Shell Nanocrystals with Photostabiliy and Electronic Accessibility. J Am Chem Soc., Vol. 119, pp.7019-7029.

Peng, Z.A., and Peng X. (2001). Mechanisms of Shape Evolution of CdSe Nanocrystals. J. Am. Chem. Soc., Vol. 123, pp. 1389-1395.

Ping Yang, Masanori Ando, Norio Murase. Encapsulation of Emitting CdTe QDs Within Silica Beads to Retain Initial Photoluminescence Efficiency. Journal of Colloid and Interface Science, Vol. 316, pp. 420-427.

Portney, N.G., and Ozkan, M. (2006). Nano-Oncology: Drug Delivery, Imaging and Sensing. Anal. Bioanal. Chem., Vol. 384, pp. 620-630.

Qu, L.H., Peng, Z.A., Peng, X.G. (2001). Synthesis Conditions for Semiconductor CdSe Nanocrystals in Organic Solvents. Nano Lett, Vol. 1, pp. 333-337.

Qu, L., Peng, X.G. (2002). Control of Photoluminescence Properties of CdSe Nanocrystals in Growth. J. Am. Chem. Soc, Vol. 124, pp. 2049-2055.

Rakovich, Yu.P., J.F. Donegan, S.A. Filonovich, M.J.M. Gomes, D.V. Talapin, A.L. Rogach, A. Eychmuller, A. (2003). Physica E, Vol. 17, pp. 99 - 100.

Roberti, T.W., Cherepy, N.J., and Zhang, J.Z. (1998). J. Chem. Phys. Vol. 108, pp. 2143-2150.

Rosenthal, S.J., McBride, J., Pennycook, S.J. and Feldman, L.C. (2007). Synthesis, surface studies, composition and structural characterization of CdSe, core/shell and biologically active nanocrystals. Surf. Sci. Rep., Vol. 62, pp. 111-157.

Rowe, B. W. , Pas, S. J. , Hill, A. J. , Suzuki, R., Freeman, B.D., Paul, D.R. (2009). Polymer Vol. 50, pp. 6149-6152. 
Rusakov, K.I., Gladyshchuk, A.A., Rakovich, Yu.P., Donegan, J.F., Filonovich, S.A., Gomes, M.J.M., Talapin, D.V., Rogach, A.L., and Eychmüller, A. (2003). Optics and Spectroscopy, Vol. 94, pp. 859-863.

Salgueiriño-Maceira, V., Correa-Duarte, M.A., Spasova, M., Liz-Marzán, L.M., M. Farle, M. (2006). Composite Silica Spheres with Magnetic and Luminescent Functionalities. Adv. Funct. Mater., Vol. 16, pp. 509-514.

Selvan, S.T., Li, C.L., Ando, M., Murase, N. (2004). Synthesis of Highly Photoluminescent Semiconductor nanoparticles by Aqueous Solution. Chem. Lett., Vol. 33, pp. 434-435.

Selvan, S.T., Tan, T.T., Ying, J.Y. (2005). Robust, Non-Cytotoxic, silica-Coated CdSe Quantum Dots with Efficient Photoluminescence. Adv. Mater., Vol. 17, pp. 16201625.

Shelby, M.D., and Wilkes, G.L. (1998). Polymer Vol. 39 No. 26, pp. 6767-6779.

Schiff, L.I. (1968). Quantum Mechanics, 3rd ed., McGraw-Hill, Inc., N.Y.

Schmid, M., S. Crampin, S., Varga, P. (2000). STM and STS of bulk electron scattering by subsurface objects. J. Electron Spectr. and Rel. Phenomena, Vol. 109, pp. 71-84

Smith, A.M. \& Nie, Sh. (2004). Chemical analysis and cellular imaging with quantum dots. Analyst, Vol. 129, No. 8, pp. 672-677.

Sundar, V.C., Eisler, H.J., Bawendi, M.G. (2002). Room-Temperature, Tunable Gain Media from Novel II-VI Nanocrystal-Titania Composite Matrices. Adv. Mater 2002, Vol. 14, pp. 739-743.

Tanaka, A., Onari, S., Arai, T. (1992). Raman Scattering from CdSe Microcrystals Embedded in a Geramante Glass Matrix. Phys. Rev. B, Vol. 45, 6587.

Tashiro, A., Nakamura, H., Uehara, M., Ogino, K., Watari, T., Shimizu, H. and Maeda, H. (2004). マイクロリアクターを用いたCdSeナノ粒子の合成（in Japanese) Kagaku Kogaku Ronbunshu, Vol. 30, pp. 113-116.

Temple, P.A. \& Hathaway, C.E. (1973). Phys. Rev. B, Vol. 7, pp. 3685-3691.

Tessler, N., Medvedev, V., Kazes, M., Kan, S.H., U. Banin, U. (2002). Efficient Near-Infrared Polymer Nanocrystal Light-Emitting Diodes. Science, Vol. 295, p. 1506.

Torchynska, T.V., Diaz Cano, A., M. Dybic, S. Ostapenko, M. Morales Rodrigez, S. Jimenes Sandoval, Y. Vorobiev, C. Phelan, A. Zajac, T. Zhukov, T. Sellers, T. (2007). phys. stat. sol. (c), 4, pp. 241-244.

Torchynska, T.V., Douda, J., Ostapenko, S., S. Jimenez-Sandoval, C. Phelan, A. Zajac, T. Zhukov, Sellers, T. (2008). J. Non-Crystal. Solids, Vol. 354, pp. 2885-2890.

Torchynska, T.V. (2009a). Interface States and Bio-Conjugation of CdSe/ZnS Core-Shell Quantum Dots. Nanotechnology, Vol. 20, 095401.

Torchynska, T.V., Douda, J., Calva, P.A., Ostapenko, S.S., and Peña Sierra, R. (2009b). Photoluminescence of Bioconjugated Core-Shell CdSe/ZnS Quantum Dots. J. Vac. Sci. ETechnol. B, Vol. 27(2), pp. 836-841.

T.V. Torchynska, J. Douda, R. Pena Siera, (2009c). Photoluminescence of CdSe/ZnS core/shell quantum dots of different sizes, phys. stat. sol. (c) Vol. 6, pp. 143-147.

Torchynska, T.V., Quintos Vazquez, A.L., Pena Sierra, R., Gazarian, K., Shcherbyna, L. (2010). Modification of Optical Properties at Bioconjugation of Core-Shell CdSe/ZnS Quantum Dots. J. of Physics, Conference Ser., Vol. 245, 012013.

Vega Macotela, L.G., Douda, J., Torchynska, T.V., Peña Sierra, R. and Shcherbyna, L. (2010a). Transformation of Photoluminescence Spectra at the Bioconjugation of Core-Shell CdSe/ZhS Quantum Dots. Phys. Stat. Sol C, Vol. 7, pp. 724-727. 
Vega Macotela, L.G., Torchynska, T.V., Douda, J. and Peña Sierra , R. (2010b). Variation of Raman spectra of CdSe/ZnS quantum dots at the bioconjugation phys.stat.solid. (c), Vol. 7, pp. 1192-1195.

Vorobiev, Y.V., Vieira, V.R., Horley, P.P., Gorley, P.N., González-Hernández, J. (2009). Energy spectrum of an electron confined in the hexagon-shaped quantum well. Science in China Series E: Technological Sciences, Vol. 52, No. 1, pp. 15-18, ISSN 10069321

Vorobiev, Y.V., Gorley, P.N., Vieira, V.R., Horley, P.P., González-Hernández, J. Torchynska, T.V., Diaz Cano, A. (2010). Effect of boundary conditions on the energy spectra of semiconductor quantum dots calculated in the effective mass approximation. Physica E, Vol. 42, No. 9, pp.2264-2267, ISSN 1386-9477

Vorobiev, Y.V., Vieira, V.R., Ribeiro, P., Gorley, V., Horley, P.P., González-Hernández, J., and Torchynska, T. (2011) Energy Spectra of an Electron in a Pyramid-shaped Quantum Dot in Effective Mass Approximation with Even Mirror Boundary Conditions. Proceedings of $3^{\text {rd }}$ WSEAS Conference on Nanotechnology, WSEAS Press, pp. 127-131, ISBN: 978-960-474-276-9, Cambridge, England, February 20 - 22 de 2011.

Walker, G.W., Sundar, V.C., Rudzinski, C.M., A.W. Wun, A.W., Bawendi, M.G., and Nocera, D.G. (2003). Quantum-dot Optical Temperature Probe. Appl. Phys. Lett. Vol. 83, No. 17, pp. 3555-3558.

Wang YA, Li JJ, Chen HY, Peng XG. (2002). J Am Chem Soc., Vol. 124, pp. 2293-2298.

Wang, S., Jarrett, B.R., Kauzlarich, S.M., and Louie, A.Y. (2007). Core/Shell Quantum Dots with High Relaxivity and Photoluminescence for Multimodality Imaging. J. Am. Chem. Soc. Vol. 129, pp. 3848-3847.

William, W.Yu., Emmanuel Chang, Rebekah Drezek, Vicki L.C. (2006). Water Soluble Quantum Dots for Biomedical Applications. Biochemical and Biophysical Research Communications, Vol. 348, pp. 781-786.

Wolcott, A., Gerion, D., Visconte, M., Sun, J., Schwartzberg, Ad., Chen, Sh., and Zhang, J.Z. (2006). Silica Coated CdTe Quantum Dots Functionalized with Thiols for Bioconjugation to IgG Proteins. J. Phys. Chem. B, Vol. 110, p.5779-5789.

Wu, X.Y., Liu, H.J., Liu, J.Q., Haley, K.N., Treadway, J.A., J.P. Larson, J.P. (2002). Immunofluorescent Labelling of Cancer Marker Her2 and Other Cellular Targets with Semiconductor Quantum Dots. Nat Biotechnol, 21, 41-46.

Yang, L., Li, Y. (2006). Simultaneous Detection of Escherichia coli 0157:H7 and Salmonella Typhimurum Using Quantum Dots as Fluorescence Labels. Analyst, Vol. 131, pp. 394-401.

Yoon, J.H., Chae, W.S., Im, S.J. and Kim, Y.R. (2005). Mild Synthesis of Ultra-Small CdSe Quantum Dots in Ethylenediamine Solution. Mater. Lett., Vol.59, pp. 1430-1433.

Yu, K., Zaman, B., Singh, S., Dashan, W. and Ripmeester, J.A. (2005). Colloidal CdSe Nanocrystals from Tri-n-Octyl J. Nanosci. Nanotechnol. Vol. 5, pp. 659-668.

Yu, W.W., Wang, A., Peng, X. (2003). Formation and Stability of Size-, Shape-, and StructureControlled CdTe Nanocrystals: Ligand Effects on Monomers and Nanocrystals. Chem. Mater., Vol. 15(22), 4300-4308.

Zenkevich, E.I., Blaudeck, T., Shulga, A.M., Cichosb, F., C. von Borczyskowski, C. (2007). Identification and Assignment of Porphyrin CdSe Hetero-Nanoassemblies. J. Luminescence, Vol. 122-123, pp. 784-788. 
Zhang, C.Y., Yeh, H.C., Kuroki, M.T., T.H. Wang., T.H. (2005). Quantum-Dot Based Nanosensor for RRE IIB RNA-Rev Peptide. Nat. Mater., Vol. 4, pp. 826-831.

Zhao, J., Bardecker, J.A., Munro, A.M., Liu, M.S., Niu, Y., Ding, I.-K., Luo, J., Chen, B., Jen, A.K.-Y., and Ginger, D.S. (2006). Efficient CdSe/CdS Quantum Dot Light-Emitting Diodes Using a Thermally Polymerized Hole Transport Layer. Nano Lett., Vol. 6, pp. 463-467. 


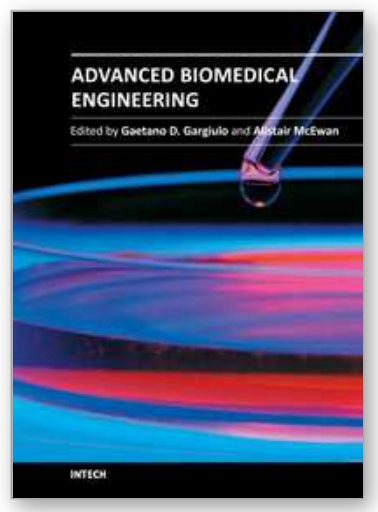

\author{
Advanced Biomedical Engineering \\ Edited by Dr. Gaetano Gargiulo
}

ISBN 978-953-307-555-6

Hard cover, 280 pages

Publisher InTech

Published online 23, August, 2011

Published in print edition August, 2011

This book presents a collection of recent and extended academic works in selected topics of biomedical signal processing, bio-imaging and biomedical ethics and legislation. This wide range of topics provide a valuable update to researchers in the multidisciplinary area of biomedical engineering and an interesting introduction for engineers new to the area. The techniques covered include modelling, experimentation and discussion with the application areas ranging from acoustics to oncology, health education and cardiovascular disease.

\title{
How to reference
}

In order to correctly reference this scholarly work, feel free to copy and paste the following:

Tetyana Torchynska and Yuri Vorobiev (2011). Semiconductor II-VI Quantum Dots with Interface States and Their Biomedical Applications, Advanced Biomedical Engineering, Dr. Gaetano Gargiulo (Ed.), ISBN: 978-953307-555-6, InTech, Available from: http://www.intechopen.com/books/advanced-biomedicalengineering/semiconductor-ii-vi-quantum-dots-with-interface-states-and-their-biomedical-applications

\section{INTECH}

open science | open minds

\section{InTech Europe}

University Campus STeP Ri

Slavka Krautzeka 83/A

51000 Rijeka, Croatia

Phone: +385 (51) 770447

Fax: +385 (51) 686166

www.intechopen.com

\section{InTech China}

Unit 405, Office Block, Hotel Equatorial Shanghai

No.65, Yan An Road (West), Shanghai, 200040, China

中国上海市延安西路65号上海国际贵都大饭店办公楼 405 单元

Phone: +86-21-62489820

Fax: $+86-21-62489821$ 
(C) 2011 The Author(s). Licensee IntechOpen. This chapter is distributed under the terms of the Creative Commons Attribution-NonCommercialShareAlike-3.0 License, which permits use, distribution and reproduction for non-commercial purposes, provided the original is properly cited and derivative works building on this content are distributed under the same license. 